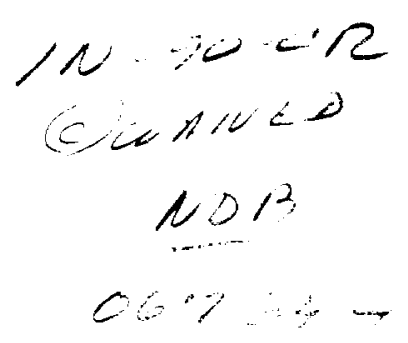

\title{
ORGANIC COMPOUNDS PRODUCED BY PHOTOLYSIS OF REALISTIC INTERSTELLAR AND COMETARY ICE ANALOGS CONTAINING METHANOL
}

\author{
Max P. Bernstein, Scott A. Sandford, louis J. Allamandola, and Sherwood Chang \\ NASA-Ames Research Center, Mail Stop 245-6, Moffett Field, CA 94035-1000 \\ AND \\ Maureen A. Scharberg \\ Department of Chemistry, San Jose State University, San Jose, CA 95192-0101 \\ Received 1995 February 10 ; accepted 1995 June 1
}

\begin{abstract}
The infrared (IR) spectra of ultraviolet (UV) and thermally processed, methanol-containing interstellar/ cometary ice analogs at temperatures from 12 to $300 \mathrm{~K}$ are presented. Infrared spectroscopy, ${ }^{1} \mathrm{H}$ and ${ }^{13} \mathrm{C}$ nuclear magnetic resonance (NMR) spectroscopy, and gas chromatography-mass spectrometry indicate that $\mathrm{CO}$ (carbon monoxide), $\mathrm{CO}_{2}$ (carbon dioxide), $\mathrm{CH}_{4}$ (methane), $\mathrm{HCO}$ (the formyl radical), $\mathrm{H}_{2} \mathrm{CO}$ (formaldehyde), $\mathrm{CH}_{3} \mathrm{CH}_{2} \mathrm{OH}$ (ethanol), $\mathrm{HC}(=\mathrm{O}) \mathrm{NH}_{2}$ (formamide), $\mathrm{CH}_{3} \mathrm{C}(=\mathrm{O}) \mathrm{NH}_{2}$ (acetamide), and $\mathrm{R}-\mathrm{C} \equiv \mathrm{N}$ (nitriles) are formed. In addition, the organic materials remaining after photolyzed ice analogs have been warmed to room temperature contain (in rough order of decreasing abundance), (1) hexamethylenetetramine (HMT, $\left.\mathrm{C}_{6} \mathrm{H}_{12} \mathrm{~N}_{4}\right)$, (2) ethers, alcohols, and compounds related to polyoxymethylene $\left\{\mathrm{POM},\left(-\mathrm{CH}_{2} \mathrm{O}-\right)_{n}\right\}$, and (3) ketones $\left\{\mathbf{R}-\mathrm{C}(=\mathrm{O})-\mathbf{R}^{\prime}\right\}$ and amides $\left\{\mathrm{H}_{2} \mathrm{NC}(=\mathrm{O})-\mathrm{R}\right\}$. Most of the carbon in these residues is thought to come from the methanol in the original ice. Deuterium and ${ }^{13} \mathrm{C}$ isotopic labeling demonstrates that methanol is definitely the source of carbon in HMT. High concentrations of HMT in interstellar and cometary ices could have important astrophysical consequences. The ultraviolet photolysis of $\mathrm{HMT}$ frozen in $\mathrm{H}_{2} \mathrm{O}$ ice readily produces the "XCN" band observed in the spectra of protostellar objects and laboratory ices, as well as other nitriles. Thus, HMT may be a precursor of XCN and a source of $\mathrm{CN}$ in comets and the interstellar medium. Also, HMT is known to hydrolyze under acidic conditions to yield ammonia, formaldehyde, and amino acids. Thus, HMT may be a significant source of prebiogenic compounds on asteroidal parent bodies. A potential mechanism for the radiative formation of HMT in cosmic ices is outlined.
\end{abstract}

Subject headings: dust, extinction - infrared: ISM : lines and bands - ISM : molecules - molecular processes

\section{INTRODUCTION}

Interstellar ice grains in dense clouds reside in environments with such low temperatures (less than $20 \mathrm{~K}$ ) that essentially anything hitting the grain, including $\mathrm{H}_{2}$, can freeze out of the gas phase (Sandford \& Allamandola 1993a; Sandford, Allamandola, \& Geballe 1993; Buch \& Devlin 1994; Dissly, Allen, \& Anicich 1994). As material accretes on the surface it is exposed to ambient ultraviolet radiation and cosmic rays (Norman \& Silk 1980; Prasad \& Tarafdar 1983). When this radiation impinges upon the ice, bonds are broken, molecules are destroyed, and new molecules, radicals, and other molecular fragments are formed. Under normal terrestrial conditions the reactive species would be very short-lived, but the low temperatures in the interstellar medium (ISM) allow some of them to persist, trapped in a cage of ice. This process may occasionally be interrupted by a thermal event (such as the passage of a shock wave, grain-grain collisions, cosmic ray interactions, or entry into a protostellar system) that causes the ice to warm to the point at which molecular fragments can begin to move, react, form new molecular species, and evaporate. Thus, in addition to species formed by grain surface reactions between accreted molecules, many of the compounds found in interstellar ices are expected to be the products of radiation and thermal processing. Insofar as cometary ices are related to interstellar ices, the same should hold true for them.

Since support is growing for the notion that comets may have brought organic materials crucial to the formation of life on Earth (see Oro 1961; Chang 1979; Chyba et al. 1990) there is great interest in characterizing the organic chemicals in comets and understanding the reactions that are expected to occur under relevant astrophysical conditions (Khare \& Sagan 1973; Hagen, Allamandola, \& Greenberg 1979; Greenberg 1982; Moore et al. 1983; Agarwal et al. 1985; d'Hendecourt et al. 1986; Johnson, Cooper, \& Lanzerotti 1986; Allamandola, Sandford, \& Valero 1988; Briggs et al. 1992; Schutte, Allamandola, \& Sandford 1993a, b; Greenberg \& Shalabiea 1994). The ultimate identification of the organic molecules which seeded the early Earth may greatly affect our understanding of how life on this planet developed.

The bulk of our knowledge about interstellar and cometary ices derives from the assignment of bands in astronomical spectra of distant objects (see Allamandola \& Sandford 1988), rather than direct chemical measurement (see Moore \& Tanabé 1990; Mitchell et al. 1992). The comparison of astronomical observations to laboratory data (especially infrared spectra) makes it clear that these ices contain predominantly $\mathrm{H}_{2} \mathrm{O}$ ice, appreciable amounts of methanol, carbon monoxide, and hydrogen, minor amounts of methane, and perhaps carbon dioxide, ammonia, and formaldehyde (ISM : Knacke et al. 1982; Allamandola \& Sandford 1988; Lacy et al. 1991; Tielens et al. 1991; Allamandola et al. 1992; d'Hendecourt \& Jourdain de Muizon 1989; Sandford, Allamandola, \& Geballe 1993; Schutte et al. 1994; Comets: Combes et al. 1988; Bregman et al. 1988; Larson et al. 1989; Reuter 1992; Hoban et al. 1993). Laboratory analog mixtures of these simple molecules frozen in proportions consistent with infrared astrono- 
mical data can be exposed to radiation appropriate to the interstellar medium and studied to determine what compounds form. Trace organic species produced in the laboratory can be characterized by infrared (IR) spectroscopy, gas chromatography-mass spectrometry (GC-MS), and nuclear magnetic resonance (NMR) spectroscopy.

In this paper we discuss the organic molecules formed by the irradiation and subsequent warming of interstellar ice analogs containing $\mathrm{H}_{2} \mathrm{O}, \mathrm{CH}_{3} \mathrm{OH}, \mathrm{CO}$, and $\mathrm{NH}_{3}$ in ratios consistent with the infrared spectra of ices in dense molecular clouds. This is the first report on the chemical analysis of the complex organic molecules produced in realistic, methanol-containing interstellar ice analogs. The following section $(\S 2)$ contains descriptions of the experimental techniques and materials used. The laboratory results are presented in $\$ 3$, and the astrophysical implications of these results are discussed in $\S 4$.

\section{EXPERIMENTAL TECHNIQUES}

A detailed description of the equipment and techniques employed for this work can be found in Allamandola et al (1988). All interstellar/cometary ice simulations discussed in this paper were carried out using the following general procedure: a CsI window was suspended in a chamber under ultra-high vacuum ( $\sim 10^{-8}$ mbar) and cooled to $12 \mathrm{~K}$ by a closed cycle helium refrigerator prior to sample deposition. The window is mounted so that it can freely rotate to face a deposition line, ultraviolet (UV) lamp, or infrared beam without breaking the vacuum. A premixed gas sample consisting of simple molecules, representative of the major constituents of interstellar ice grains, was deposited onto the cooled CsI substrate. Typical ices contained $\mathrm{H}_{2} \mathrm{O}, \mathrm{CH}_{3} \mathrm{OH}, \mathrm{CO}$, and $\mathrm{NH}_{3}$ in varying relative proportions.

The infrared spectrum of the resulting amorphous mixed ice was measured using a Nicolet 7000 FTIR spectrometer at 0.9 $\mathrm{cm}^{-1}$ resolution (the observed full width at half-maximum of an unresolved feature). Ultraviolet radiation, generated by a microwave-powered hydrogen-flow discharge lamp, was used to simulate the affects of the interstellar radiation field. The lamp is equipped with a $\mathbf{M g F}_{2}$ window and was typically operated at $70 \mathrm{~W}$. The hydrogen pressure was held at $\sim 100$ mtorr by continuous pumping on the lamp while hydrogen was injected at a controlled rate. Under these conditions the flux is evenly divided between the Lyman- $\alpha$ line at $1216 \AA$ and a $\sim 200 \AA$ wide collection of molecular transitions centered at about $1600 \AA$. The total flux produced by the lamp is $\sim 2 \times 10^{15}$ photons $\mathrm{cm}^{-2} \mathrm{~s}^{-1}$ (Warnek 1962). The effects of UV radiation on the ices was monitored by obtaining an infrared spectrum at various intervals during photolysis. After irradiation, most samples were then warmed in steps, while the affects of warming were monitored using infrared spectroscopy. All of the starting materials and many of the products are volatile and as a result they evaporate before the substrate reaches room temperature.

Ice samples must be fairly thin for the UV photons to penetrate, and only a few percent of the starting materials are converted into organic residue. As a result any ice sample that was thin enough to provide a good infrared spectrum at $12 \mathrm{~K}$ yields very little infrared absorption at $300 \mathrm{~K}$. This is because most of the material evaporates, leaving only a trace residue behind. Although spectra of such small amounts of material make it possible to determine the general classes of compounds formed, they are generally not adequate for the identification of individual molecular species. In order to increase the amount of organic material produced and improve the spectral signal-to-noise ratio, individual thin layers of ice were deposited and photolyzed for $\sim 10$ hours each at $12 \mathrm{~K}$ before the next layer of ice was deposited on top. This procedure was repeated $\sim 20$ times over a period of $\sim 200$ hours, producing a thicker, layered ice where each layer has been exposed to UV radiation at $12 \mathrm{~K}$. After photolysis of the last layer was complete, the entire sample was then warmed (at $2 \mathrm{~K} \mathrm{minute}^{-1}$ ) to various intermediate temperatures up to $300 \mathrm{~K}$. Infrared spectra were typically taken at each intermediate temperature, although below $200 \mathrm{~K}$ these samples typically produced spectra with saturated absorption features because the samples are too thick until most of the volatile starting materials evaporate away.

During warm-up it was possible to collect the volatiles that evaporated from the sample at any temperature above $70 \mathrm{~K}$ by condensing them into previously evacuated sample fingers cooled with liquid nitrogen. The sample fingers were attached to the vacuum system through a small Pyrex manifold equipped with greaseless glass stopcocks on both ends. The analysis of these volatiles will be described in a separate publication.

After the photolyzed sample had been warmed to $300 \mathrm{~K}$ under dynamic vacuum a nonvolatile organic residue consisting of only a few percent of the original gas mixture typically remains on the CsI window (Allamandola et al. 1988). After an infrared spectrum of this organic residue was acquired, the vacuum chamber was isolated from the pumps, filled with inert gas, and wrapped in a glove bag that had been purged three times with the same inert gas. The CsI substrate was then removed from the vacuum chamber, washed repeatedly with a deuterated solvent ( $\mathrm{CD}_{3} \mathrm{OD}$ or DMSO-Cambridge Isotope Labs) in the inert atmosphere to dissolve the residue. The solution was then subjected to GC-MS and nuclear magnetic resonance (NMR) spectroscopic analysis.

The GC-MS analyses were performed using a Hewlett Packard 5971 series II gas chromatograph-mass spectrometer. GC separations were performed on HP-5 (5\% phenyl methyl silicone), J\&W DBwax (polyethyleneglycol), and J\&W DB-17 ( $50 \%$ phenyl silane) capillary columns which had lengths of 30 $\mathrm{m}$, inner diameters of $0.25 \mathrm{~mm}$, and inner coatings $0.25 \mu \mathrm{m}$ thick. Most samples were studied twice, first by running the residue sample through the polyethyleneglycol column using only a single solvent (methanol or DMSO), and then again after the sample had undergone derivatization. To derivatize, the solvent used to remove the residue from the sample window was evaporated and the residue was then dissolved in $\mathrm{CH}_{3} \mathrm{CN}$. This solution was then mixed with $\mathrm{N}$-(tert-butyldimethylsilyl)-N-methyltrifluoroacetamide with $1 \%$ tertbutyldimethylsilyl chloride, which replaces alcohol or amine groups with a tert-butyl-dimethylsilyl group. This allows for a more sensitive detection of many nonvolatile species.

A Brucker Omega $300 \mathrm{MHz}$ spectrometer was used to obtain all the NMR data. The NMR spectra were recorded with the spectrometer operating at $75.6 \mathrm{MHz}$ for ${ }^{13} \mathrm{C}$ nuclei detection. The ${ }^{13} \mathrm{C}$ spectra consisted of 25,000 to 30,000 scans of 8192 complex data points over a $20,000 \mathrm{kHz}$ bandwidth using a 3.50 microsecond $17^{\circ}$ pulse at $22^{\circ} \mathrm{C} \cdot{ }^{13} \mathrm{C}$ chemical shifts were referenced to naturally abundant dimethyl sulfoxide $\left[\left({ }^{13} \mathrm{CH}_{3}\right)_{2} \mathrm{SO}\right]$ which resonated at $40.0 \mathrm{ppm}$ at $22^{\circ} \mathrm{C}$.

The compounds used to produce our mixed molecular ices had the following purities: $\mathrm{H}_{2} \mathrm{O}$ (liquid, triply vacuum distilled), $\mathrm{CH}_{3} \mathrm{OH}$ (liquid, Fisher Photrex grade, $99.98 \%$ 
purity, triply vacuum distilled), $\mathrm{CO}$ (gas, Matheson C.P., 99.5\% purity), and $\mathrm{NH}_{3}$ (gas, Matheson anhydrous, $99.99 \%$ purity). Since the partial pressures of mixture components typically fell in the 1 to 100 mbar range in our sample bulbs and our sample preparation system routinely operates in the $10^{-5}$ mbar range, sample contamination from the vacuum system was limited to 1 part in $10^{5}-10^{7}$. Our control sample of pure hexamethylenetetramine (HMT, Fischer Scientific, $99+\%$ purity) was generously provided to us by B. N. Khare of Cornell University so that we might use it as a standard for comparison to our residues. Samples used as standards for other compounds identified or tentatively identified in our residues were formamide (Aldrich, 98\% purity), acetamide (Aldrich, 98\% purity), and ethanol (Quantum Chemical, 200 Proof dehydrated). Isotopic species used included deuterium oxide ( $\mathrm{D}_{2} \mathrm{O}$, Sigma, 99.8\% purity), methanol- $d_{1}\left(\mathrm{CH}_{3} \mathrm{OD}\right.$, Cambridge Isotope Labs, $99 \%$ purity), methanol- $d_{4}\left(\mathrm{CD}_{3} \mathrm{OD}\right.$, Cambridge Isotope Labs, $99.8 \%$ purity), perdeuterated hexamethylenetetramine (HMT- $d_{12}$, Cambridge Isotope Labs, 98\% purity), and ${ }^{13} \mathrm{C}$-methanol $\left({ }^{13} \mathrm{CH}_{3} \mathrm{OH}\right.$, Cambridge Isotope Labs, $99 \%$ purity). Solvents and derivatizing agents used to produce the GC-MS and NMR samples included methanol (Mallinckrodt, 99.9\% purity), DMSO-d $d_{6}$ (Cambridge Isotope Labs, $99.96 \%$ purity), $\mathrm{CH}_{3} \mathrm{CN}$ (Aldrich, $99+\%$ purity), and $\mathrm{N}$-(tert-butyldimethylsilyl)-N-methyltrifluoroacetamide with $1 \%$ tert-butyldimethylsilyl chloride (Regis Chemical, 98\% purity).

\section{EXPERIMENTAL RESULTS}

Infrared spectroscopy was used to identify a number of small molecules produced by UV radiation of interstellar ice analogs at low temperature. Experiments employing isotopically labeled starting materials suggest pathways by which these materials are formed. In addition, IR spectroscopy, in conjunction with NMR and GC-MS, has allowed us to identify one of the major components and some of the minor components of the nonvolatile organic residue that remains at room temperature.

\subsection{Infrared Spectra of Photolyzed Ices}

Figure $1 a$ shows an infrared spectrum of the ice composed of $\mathrm{H}_{2} \mathrm{O}: \mathrm{CH}_{3} \mathrm{OH}: \mathrm{CO}: \mathrm{NH}_{3}=100: 50: 10: 10$ deposited at $12 \mathrm{~K}$. This represents our canonical interstellar/cometary ice analog as it matches the infrared spectra of ices in many dense molecular clouds (Allamandola \& Sandford 1988). A spectrum of the same mixture after UV photolysis at $12 \mathrm{~K}$ for $22 \mathrm{hr}$ is given in Figure $1 b$. Ultraviolet irradiation of these ices produces $\mathrm{CO}$ [characteristic band near $\left.2140 \mathrm{~cm}^{-1}(4.67 \mu \mathrm{m})\right], \mathrm{CO}_{2}$ [bands near 2340 and $665 \mathrm{~cm}^{-1}(4.27$ and $\left.15.0 \mu \mathrm{m})\right], \mathrm{CH}_{4}$ [bands near 3015 and $1305 \mathrm{~cm}^{-1}$ (3.32 and $\left.7.66 \mu \mathrm{m}\right)$ ), and $\mathrm{H}_{2} \mathrm{CO}$ [bands near 1720 and $1500 \mathrm{~cm}^{-1}(5.81$ and $\left.6.67 \mu \mathrm{m})\right]$, as well as the HCO radial [bands near 1870 and $1090 \mathrm{~cm}^{-1}$ (5.35 and 9.17 $\mu \mathrm{m})]$. Many of these bands are too weak to be seen in Figure $1 b$ but have been described in detail by Allamandola et al. (1988). The photolysis of a $\mathrm{H}_{2} \mathrm{O}: \mathrm{CH}_{3} \mathrm{OH}=100: 50$ mixture under the same conditions (not shown) produces these species $\left(\mathrm{H}_{2} \mathrm{CO}, \mathrm{CO}, \mathrm{CO}_{2}, \mathrm{CH}_{4}\right.$, and $\left.\mathrm{HCO}\right)$ at essentially the same rate as the standard mixture containing $\mathrm{NH}_{3}$ and $\mathrm{CO}$. Infrared spectra of irradiated ices made from ${ }^{13} \mathrm{C}$ and $\mathrm{D}$ labeled starting materials (not shown) confirm that none of the photoproducts are the result of contamination. These experiments strongly imply that the carbon in all the above photo-products is

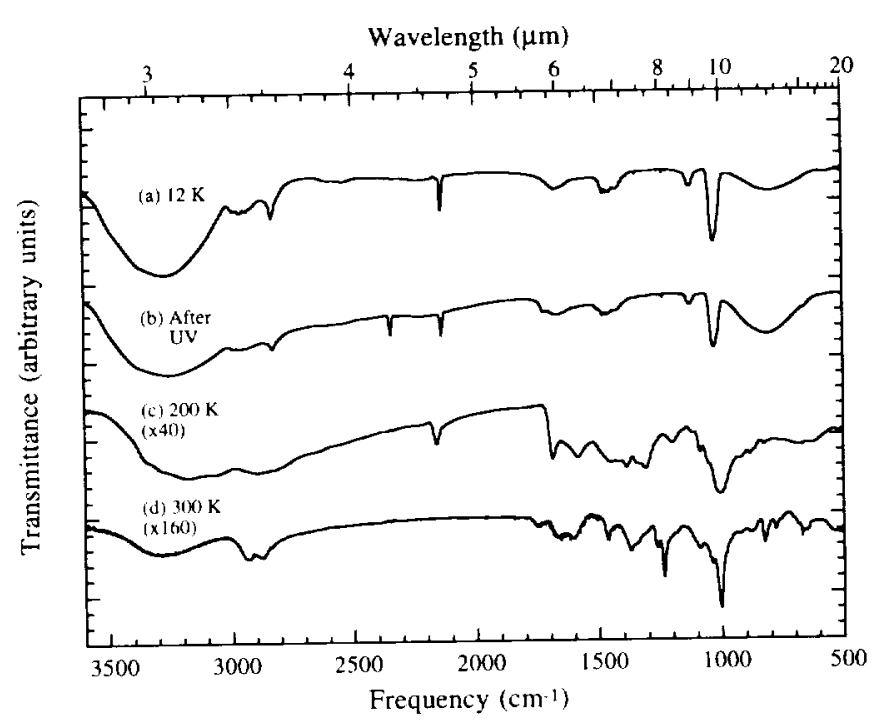

FIG. $1 .-3600-500 \mathrm{~cm}^{-1}(2.78-20.0 \mu \mathrm{m})$ infrared spectrum of: (a) a single layer $\mathrm{H}_{2} \mathrm{O}: \mathrm{CH}_{3} \mathrm{OH}: \mathrm{CO}: \mathrm{NH}_{3}=100: 50: 10: 10$ ice mixture at $12 \mathrm{~K}$ before photolysis, (b) the same single ice layer after UV photolysis at $12 \mathrm{~K} \mathrm{for} \sim 20 \mathrm{hr}$, (c) a 20 layer ice mixture after UV photolysis and warm up to $200 \mathrm{~K}$, and $(d)$ a 20 layer ice mixture after UV photolysis and warm up to $300 \mathrm{~K}$.

derived largely from methanol, and that neither $\mathrm{CO}$ nor $\mathrm{NH}_{3}$ need be present to form these photolysis products.

In addition to the $\mathrm{C}$ - and $\mathrm{O}$-containing species mentioned above, photolysis of the standard ice analog also produces some features that require the presence of $\mathrm{NH}_{3}$ in the starting materials. These include features too weak to be apparent in Figure 1 that are attributed to nitriles. A band near $2235 \mathrm{~cm}^{-1}$ $(4.47 \mu \mathrm{m})$ is consistent with a vinyl cyanide $(\mathrm{RHC}=\mathrm{CH}-\mathrm{CN})$, while one near $2160 \mathrm{~cm}^{-1}(4.63 \mu \mathrm{m})$ indicates the presence of the well-known "XCN" feature (see Tegler et al. 1993). Other compounds having bands that are visible only after warming are also produced (see Fig. $1 c$ and text below).

\subsection{Infrared Spectra of Warmed Residues}

The spectrum and composition of the irradiated ice mixtures change greatly with increasing temperature, as seen in Figure 1 . With warming, the peaks corresponding to unstable species such as $\mathrm{H}_{2} \mathrm{CO}$ and the methyl and formyl radicals vanish as they react and bands due to volatile compounds such as $\mathrm{CO}$, $\mathrm{CH}_{4}$, and $\mathrm{CO}_{2}$ diminish as they evaporate (Allamandola et al. 1988). In addition, new peaks appear during warming as the more abundant volatiles sublime away or as new bonds are formed by reactive species that become mobilized as the temperature increases. These new absorption features can be interpreted in terms of the presence of new functional groups (see Bellamy 1960 and Silverstein \& Bassler 1963 for thorough discussions of the infrared bands produced by different chemical functional groups).

\subsubsection{Infrared Spectra of Residues at $200 \mathrm{~K}$}

Warming to $200 \mathrm{~K}$ (Fig. 1c) results in the complete loss of the features representative of the starting materials and volatile photoproducts such as $\mathrm{CO}, \mathrm{CO}_{2}, \mathrm{HCO}, \mathrm{H}_{2} \mathrm{CO}, \mathrm{CH}_{3}$, and $\mathrm{CH}_{4}$. The feature near $2160 \mathrm{~cm}^{-1}(4.63 \mu \mathrm{m})$, which is designated as XCN in the literature, remains on the window at this temperature at $\sim 10^{-7}$ mbar. Substantial reduction of the broad $\mathrm{O}-\mathrm{H}$ stretch at $\sim 3250 \mathrm{~cm}^{-1}(3.08 \mu \mathrm{m})$, the $\mathrm{C}-\mathrm{H}$ stretching bands near 2950 and $2830 \mathrm{~cm}^{-1}(3.39$ and $3.53 \mu \mathrm{m})$, 
the $\mathrm{H}-\mathrm{O}-\mathrm{H}$ bending band at $1660 \mathrm{~cm}^{-1}(6.02 \mu \mathrm{m})$, and $\mathrm{C}-\mathrm{O}$ bending band at $1025 \mathrm{~cm}^{-1}(9.756 \mu \mathrm{m})$ suggests that most of the methanol and water has also evaporated, just as it does in control experiments where the sample is not photolyzed. The peak near $1005 \mathrm{~cm}^{-1}(9.95 \mu \mathrm{m})$, which dominates the spectrum at and above $200 \mathrm{~K}$, is not the $\sim 1025 \mathrm{~cm}^{-1}$ $(9.756 \mu \mathrm{m})$ band of methanol seen below $200 \mathrm{~K}$. We demonstrate in $\S 4.1 .3$ that it is instead caused by a compound bearing a $\mathrm{C}-\mathrm{N}$ single bond. The $1720 \mathrm{~cm}^{-1}(5.81 \mu \mathrm{m}) \mathrm{C}=\mathrm{O}$ stretching band of formaldehyde is replaced by a $\mathrm{C}=\mathrm{O}$ stretching band near $1685 \mathrm{~cm}^{-1}(5.93 \mu \mathrm{m})$. This, and the appearance of an $\mathrm{H}-\mathrm{N}-\mathrm{H}$ scissoring feature at $1585 \mathrm{~cm}^{-1}$ $(6.31 \mu \mathrm{m})$, are consistent with the formation of amides such as formamide $\quad\left\{\mathrm{HC}(=\mathrm{O}) \mathrm{NH}_{2}\right\}$ and/or acetamide $\left\{\mathrm{CH}_{3} \mathrm{C}(-\mathrm{O}) \mathrm{NH}_{2}\right\}$. However, the strength of the $1585 \mathrm{~cm}^{-1}$ band is too great relative to the $1685 \mathrm{~cm}^{-1}$ band for a typical amide, implying the presence of some $\mathrm{NH}_{2}$ groups in materials other than amides. The spectra also contain distinct features near 1450 and $1385 \mathrm{~cm}^{-1}$ (6.90 and $7.22 \mu \mathrm{m}, \mathrm{C}-\mathrm{H}$ deformation and scissoring motions) as well as shoulders near 1090 1055 , and $885 \mathrm{~cm}^{-1}(9.22,9.48$, and $11.3 \mu \mathrm{m}, \mathrm{C}-\mathrm{O}$ stretches $)$ that are consistent with the presence of small amounts of ethanol $\left(\mathrm{CH}_{3} \mathrm{CH}_{2} \mathrm{OH}\right)$. A potential $\mathrm{C}-\mathrm{H}$ deformation vibration band is seen near $1305 \mathrm{~cm}^{-1}(7.66 \mu \mathrm{m})$ and a possible $\mathrm{C}-\mathrm{O}$ stretching absorption lies near $1195 \mathrm{~cm}^{-1}(8.37 \mu \mathrm{m})$. Additional weak, unassigned bands fall near $825,680,635$, and $520 \mathrm{~cm}^{-1}(12.1,14.7,15.7$, and $19.2 \mu \mathrm{m})$.

\subsubsection{Infrared Spectra of Residues at $300 \mathrm{~K}$}

After these samples are warmed to $300 \mathrm{~K}$, the strongest peak remaining is typically only $2 \%-3 \%$ the strength of the original $1025 \mathrm{~cm}^{-1} \mathrm{CH}_{3} \mathrm{OH}$ ice feature. The total absorption produced by the $300 \mathrm{~K}$ samples is typically 2 to 5 times weaker than seen in the sample at $200 \mathrm{~K}$, indicating that a considerable amount of material is lost between 200 and $300 \mathrm{~K}$. The organic film that remains on the CsI substrate at $300 \mathrm{~K}$ is composed primarily of nonvolatile compounds, although some volatile materials are trapped in the more " refractory" organic matrix. When ammonia was among the starting materials, the most prominent feature of the $300 \mathrm{~K}$ residue is the sharp, strong absorption at $1005 \mathrm{~cm}^{-1}(9.95 \mu \mathrm{m}$ ) (Figs. $1 d, 2 a$, and $2 b$ ). The infrared spectrum indicates that the residue contains many different functional groups (Fig. $2 a$ ). Prominent bands include an $\mathrm{O}-\mathrm{H}$ stretch at $\sim 3280 \mathrm{~cm}^{-1}(3.05 \mu \mathrm{m}), \mathrm{C}-\mathrm{H}$ stretches near 2935 and $2870 \mathrm{~cm}^{-1}(3.41$ and $3.48 \mu \mathrm{m})$, and the $\mathrm{C}=\mathrm{O}$ stretch of a possible ketone or ester at $\sim 1740 \mathrm{~cm}^{-1}(5.75 \mu \mathrm{m})$. The band at $\sim 1665 \mathrm{~cm}^{-1}(6.01 \mu \mathrm{m})$ is also consistent with a $\mathrm{C}=\mathrm{O}$ stretch, in this case in an amide. The band near 1600 $\mathrm{cm}^{-1}(6.25 \mu \mathrm{m})$ is most likely due to N-H scissoring vibrations in an $\mathrm{NH}_{2}$ group and the bands near 1460 and $1370 \mathrm{~cm}^{-1}(6.85$ and $7.30 \mu \mathrm{m})$ are probably due to $\mathrm{C}-\mathrm{H}$ deformation and scissors motions, respectively, of methyl $\left(-\mathrm{CH}_{3}\right)$ and methylene $\left(-\mathrm{CH}_{2}-\right)$ groups. The sharp absorptions near 1260 and 1235 $\mathrm{cm}^{-1}(7.94$ and $8.10 \mu \mathrm{m})$ are probably due to $\mathrm{C}-\mathrm{N}$ stretches or the $\mathrm{C}-\mathrm{O}$ stretch in $\mathrm{O}=\mathrm{C}-\mathrm{O}$ groups. The strong, broad, multicomponent feature spanning the range from 1150 to 900 $\mathrm{cm}^{-1}(8.70$ to $11.1 \mu \mathrm{m})$ and peaked near $1005 \mathrm{~cm}^{-1}(9.95 \mu \mathrm{m})$ could contain contributions from both $\mathrm{C}-\mathrm{O}$ and $\mathrm{C}-\mathrm{N}$ stretching vibrations. The band near $825 \mathrm{~cm}^{-1}(12.1 \mu \mathrm{m})$ may be due to $\mathrm{CH}_{2}$ rocking, and the peaks near $670 \mathrm{~cm}^{-1}(14.9 \mu \mathrm{m})$ are probably caused by $\mathrm{CNC}$ deformations. The band near 780 $\mathrm{cm}^{-1}(12.8 \mu \mathrm{m})$ remains unidentified.

Surprisingly, a 4.5-fold increase in the initial ammonia concentration does not cause significant qualitative changes in the

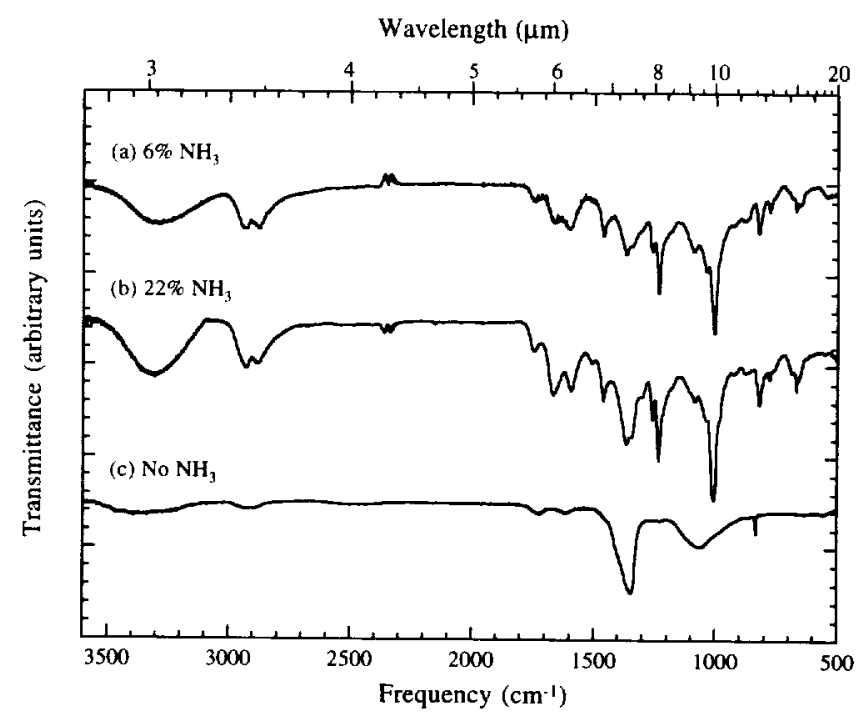

Fig. 2.-Dependence on $\mathrm{NH}_{3}$ of the $3600-400 \mathrm{~cm}^{-1}(2.78-25.0 \mu \mathrm{m})$ infrared spectra of $300 \mathrm{~K}$ residues produced by the UV photolysis of $\mathrm{H}_{2} \mathrm{O}: \mathrm{CH}_{3} \mathrm{OH}: \mathrm{CO}: \mathrm{NH}_{3}$ ice mixtures. The ice starting compositions were: $(a)$ $\mathrm{H}_{2} \mathrm{O}: \mathrm{CH}_{3} \mathrm{OH}: \mathrm{CO}: \mathrm{NH}_{3}=100: 50: 10: 10$, (b) $\mathrm{H}_{2} \mathrm{O}: \mathrm{CH}_{3} \mathrm{OH}: \mathrm{CO}: \mathrm{NH}_{3}=$ $100: 50: 10: 45$, and (c) $\mathrm{H}_{2} \mathrm{O}: \mathrm{CH}_{3} \mathrm{OH}: \mathrm{CO}: \mathrm{NH}_{3}=100: 50: 10: 0$.

appearance of the infrared spectrum of the residue at $300 \mathrm{~K}$, although some small changes were observed (compare Figs. $2 a$ and $2 b)$. For example, the $2935 \mathrm{~cm}^{-1}(3.41 \mu \mathrm{m}) \mathrm{C}-\mathrm{H}$ stretch grows relative to that at $2870 \mathrm{~cm}^{-1}(3.48 \mu \mathrm{m})$ while the 3300 , 1665 , and $1370 \mathrm{~cm}^{-1}(3.03,6.01$, and $7.30 \mu \mathrm{m})$ peaks grow considerably, consistent with the suggestion that the growth of all these bands is caused by an increase in the concentration of amides or other compounds that depend on ammonia for formation.

In contrast, the infrared spectrum of the residue changes dramatically when ammonia is completely eliminated from the starting ice mixture (Fig. 2c). The simpler infrared spectrum that results from the removal of $\mathrm{NH}_{3}$ contains a broad $\mathrm{O}-\mathrm{H}$ stretching peak centered near $3350 \mathrm{~cm}^{-1}(2.99 \mu \mathrm{m})$ that is suggestive of an alcohol, a small structured $\mathrm{C}-\mathrm{H}$ stretching feature centered at $\sim 2920 \mathrm{~cm}^{-1}(3.42 \mu \mathrm{m})$, a weak feature near $1720 \mathrm{~cm}^{-1}(5.81 \mu \mathrm{m})$ due to a ketone or ester $\mathrm{C}=\mathrm{O}$ stretch, an unidentified weak feature near $1610 \mathrm{~cm}^{-1}(6.21 \mu \mathrm{m})$, an unusually strong peak at $\sim 1345 \mathrm{~cm}^{-1}(7.43 \mu \mathrm{m})$ indicative of the presence of $\mathrm{C}-\mathrm{H}$ deformation modes, and a broader feature of intermediate strength at $\sim 1065 \mathrm{~cm}^{-1}(9.39 \mu \mathrm{m})$ consistent with the asymmetric $\mathrm{C}-\mathrm{O}$ stretch of an ether. The sharp band near $835 \mathrm{~cm}^{-1}(12.0 \mu \mathrm{m})$ remains unidentified. The fact that the $\mathrm{C}-\mathrm{H}$ deformation feature at $\sim 1345 \mathrm{~cm}^{-1}$ is much stronger than the $\mathrm{C}-\mathrm{H}$ stretching features near 2920 $\mathrm{cm}^{-1}$, rather than the reverse, suggests that strong interactions with electronegative groups are involved. Taken together these bands suggest the presence of an ether or a compound with both either and alcohol groups. Overall, the residue made without ammonia in the starting mixture produces weaker infrared absorptions than a $\mathrm{N}$-containing residue made from a comparable mass of starting materials. Thus, in broad terms, the residue generated from photolysis and warming of an $\mathrm{H}_{2} \mathrm{O}: \mathrm{CH}_{3} \mathrm{OH}: \mathrm{CO}: \mathrm{NH}_{3}=100: 50: 10: 10$ mixture seems to be composed primarily of compounds that depend strongly on the presence of $\mathrm{NH}_{3}$ in the starting materials and, to a lesser extent, of compounds independent of the $\mathrm{NH}_{3}$.

The spectrum of the $\mathrm{N}$-free residue provides important clues to nature of the carriers that produce the overall absorption 
between 1150 and $900 \mathrm{~cm}^{-1}(8.70-11.1 \mu \mathrm{m})$ in the $\mathrm{N}$ containing residues. This broad absorption has a profile that suggests overlapping features from both $\mathrm{C}-\mathrm{O}$ and $\mathrm{C}-\mathrm{N}$ single bonds may contribute in this region. Since all the carbon in the starting mixture was originally oxidized, this feature could contain ethers or polyethers (molecules containing $-\mathrm{OCH}_{3}$ groups), i.e., materials similar to those suggested for the $\mathrm{N}$-free residue, and POM-like materials $\left\{\left(-\mathrm{CH}_{2} \mathrm{O}-\right)_{n}\right.$ with various other functional groups substituting for $\mathrm{H}$ or terminal groups\}. However, this feature, which dominates the spectrum when ammonia is present in the starting materials, is greatly diminished when $\mathrm{NH}_{3}$ is absent (compare Figs. $2 a$ and $2 b$ with Fig. $2 c$ ). This suggests that much of this feature is caused by $\mathbf{C}-\mathrm{N}$ single bond stretches. It will be shown later (\$ 3.3.2) that this is indeed the case. However, the implication that the remainder of the absorption between 1150 and 900 $\mathrm{cm}^{-1}(8.70-11.1 \mu \mathrm{m})$ is also due to $\mathrm{C}-\mathrm{N}$ stretching does not necessarily follow since some of this absorption could be due to the same materials produced in the $\mathrm{N}$-free residues. In addition, it has been previously demonstrated that $\mathrm{NH}_{3}$ is an important catalyst in the formation of POM-like materials during the warm up of $\mathrm{H}_{2} \mathrm{CO}$-containing interstellar ice analogs (Schutte, Allamandola, \& Sandford 1993a, b). Since the photolyzed ices contain $\mathrm{H}_{2} \mathrm{CO}$, much of the 1150 to 900 $\mathrm{cm}^{-1}$ absorption in the $\mathrm{N}$-containing residues could be due to $\mathrm{C}-\mathrm{O}$ stretching in POM-like materials. Thus, the disap- pearance of much of the 1150 to $900 \mathrm{~cm}^{-1}$ absorption when $\mathrm{NH}_{3}$ is removed from the starting ice does not necessarily imply the source(s) of the absorption contain nitrogen.

\subsection{Mass Spectroscopy of the $300 \mathrm{~K}$ Residue}

Gas chromatography-mass spectrometry (GC-MS) was used to separate and identify several of the components of the residues. The GC technique separates the various components of a mixture based on the speed with which they pass through a capillary column (which depends on the compound's affinity for the material in the column). As they exit the column the individual components enter the mass spectrometer, are ionized and accelerated through a magnetic field where the extent of deflection yields the mass of the compound and its fragments.

Figures $3 a$ and $3 b$ show the GC-MS analysis of the $300 \mathrm{~K}$ residue generated from the photolysis of an $\mathrm{H}_{2} \mathrm{O}: \mathrm{CH}_{3} \mathrm{OH}$ : $\mathrm{CO}: \mathrm{NH}_{3}=100: 50: 10: 10$ mixture. In Figure $3 a$, the different components of the residue are separated by the time it takes for them to pass through the chromatographic column (retention time). The width of a peak (unlike its retention time) is not an intrinsic property of the molecule, but instead depends on the amount of material injected into the column, with greater amounts giving larger widths. Figure $3 b$ shows the mass spectrum of the molecular fragments produced by the material responsible for the largest peak in Figure $3 a$ (at a retention
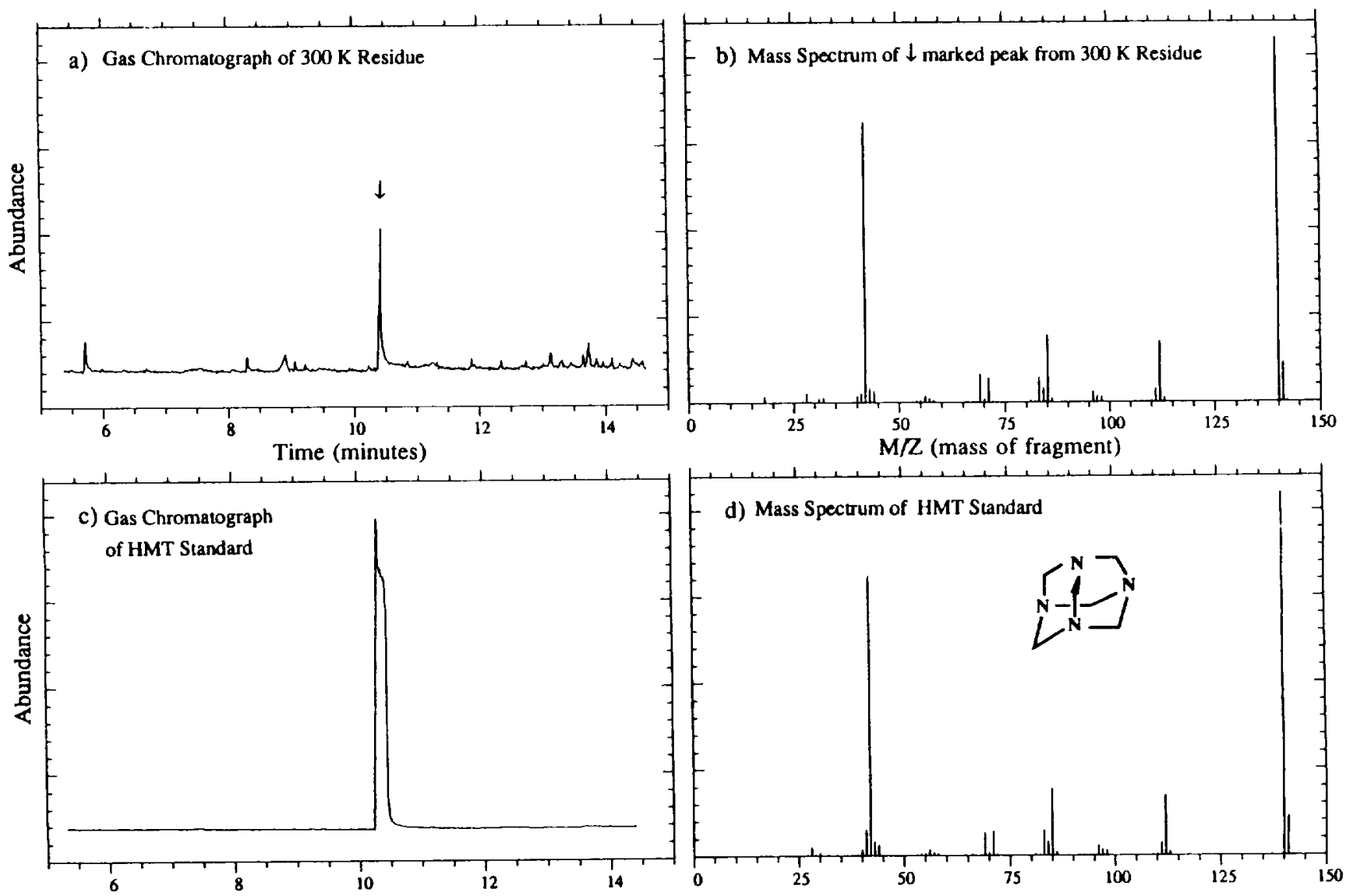

Fig. 3-Gas chromatographs and mass spectra of the refractory residue produced by the irradiation of an $\mathrm{H}_{2} \mathrm{O}: \mathrm{CH}_{3} \mathrm{OH}: \mathrm{CO}: \mathrm{NH}_{3}=100: 50: 10: 10$ ice followed by warming to $300 \mathrm{~K}$ compared to a sample of pure hexamethylenetetramine (HMT). The gas chromatographs of the residue and HMT standard are shown in panels $(a)$ and $(c)$, respectively, and the corresponding mass spectra of the most prominent peaks (retention time of about 10.2 minutes) are shown in $(b)$ and $(d)$. The structure of HMT is given in (d). 


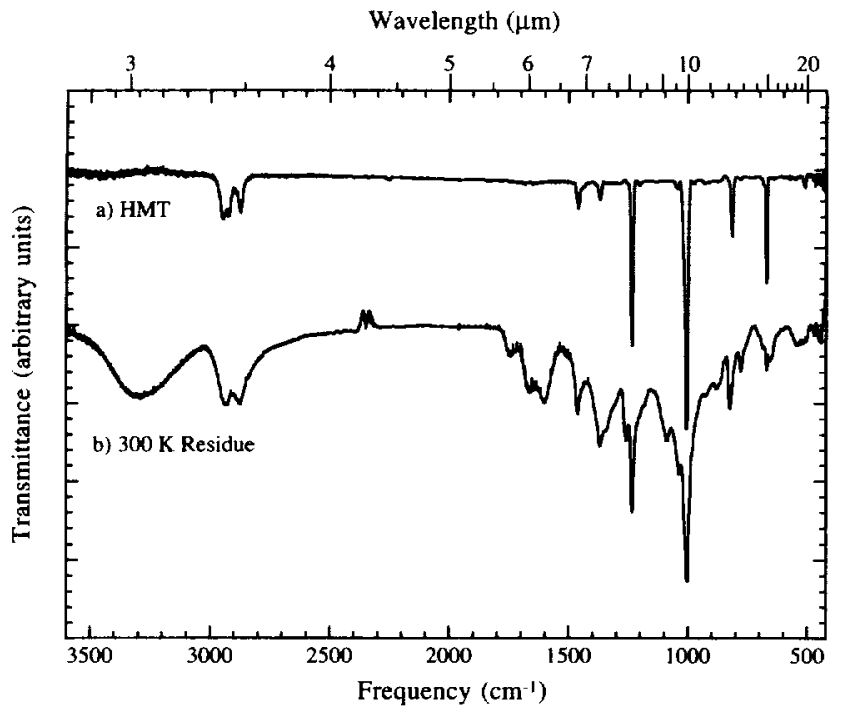

Fig. 4. $-3600-400 \mathrm{~cm}^{-1}(2.78-25.0 \mu \mathrm{m})$ infrared spectrum of $(a)$ a sample of pure HMT frozen in $\mathrm{H}_{2} \mathrm{O}$ at $12 \mathrm{~K}$ and subsequently warmed to $300 \mathrm{~K}$, and (b) the residue generated from photolysis of an $\mathrm{H}_{2} \mathrm{O}: \mathrm{CH}_{3} \mathrm{OH}: \mathrm{CO}: \mathrm{NH}_{3}=$ 100:50: 10:10 mixture that was subsequently warmed to $300 \mathrm{~K}$ (same as shown in Fig. 1d). The spectrum of HMT is adapted from Bernstein et al. (1994).

time of $\sim 10.2$ minutes). The mass spectrum indicates that the mass of the parent species is $140 \mathrm{amu}$. The absence of fragmentation peaks corresponding to the loss of $\mathrm{CH}_{3}, \mathrm{CH}_{3} \mathrm{CH}_{2}$, etc. indicate that there are no hydrocarbon moieties appended to the skeleton of this compound. This suggests that it probably has a ring or cage structure, and because it has an even mass, it must have an even number of nitrogens. Based on this information, and the infrared spectrum of the $300 \mathrm{~K}$ residue, we were able to identify this component as hexamethylenetetramine, (HMT; $\mathrm{C}_{6} \mathrm{H}_{12} \mathrm{~N}_{4}$; see structural insert in Fig. $3 d$ ).

HMT, a nitrogen-rich organic cage molecule, is a white crystalline solid that sublimes at $\sim 280^{\circ} \mathrm{C}$. The GC-MS spectra of pure HMT provide an excellent match to those of the $300 \mathrm{~K}$ residue (Figs. $3 b$ and $3 d$ ). The comparison of the infrared spectrum of HMT (Bernstein et al. 1994) with that of the $300 \mathrm{~K}$ residue shows that most of the prominent narrow peaks in the residue spectrum are due to HMT (Fig. 4). Clearly, HMT comprises a considerable portion of the residue at room tem- perature. However, the spectral features of pure HMT clearly do not account for all the absorption features seen at $300 \mathrm{~K}$, indicating the residue contains additional components.

GC-MS studies of the residues resulting from photolysis and warming of an astrophysical mixture where all of the starting $H$ atoms had been replaced by deuterium (Fig. 5) shows that the resulting HMT is fully deuterated, as indicated by the fact that it has an atomic mass of $152 \mathrm{amu}\left(\mathrm{HMT}-\mathrm{d}_{12}\right)$. This proves that the residue is formed from the starting materials (not impurities, which would be protonated) and adds further confirmation to the identification of HMT. Similarly, residues made from starting materials where only exchangeable protons are labeled (i.e., $\mathrm{D}_{2} \mathrm{O}: \mathrm{CH}_{3} \mathrm{OD}: \mathrm{CO}: \mathrm{ND}_{3}=100: 50: 10: 10$ ) produces unlabeled HMT, demonstrating that the protons in the HMT molecule are derived from the methyl group in methanol. In addition, GC-MS of a residue made from a starting mixture containing ${ }^{13} \mathrm{C}$-labeled methanol produced HMT with an atomic mass of $146 \mathrm{amu}$, indicating that it had ${ }^{13} \mathrm{C}$ in place of ${ }^{12} \mathrm{C}$, again confirming that the carbon in the HMT is derived from the methanol.

In a similar fashion, direct GC-MS techniques also verified the presence of small amounts of ethanol $\left(\mathrm{CH}_{3} \mathrm{CH}_{2} \mathrm{OH}\right)$ in our samples (mass spectra not shown). Comparison with ethanol standards provided good retention time matches and both the standards and residue components showed the characteristic mass spectrum dominated by the parent at 46 amu and major fragmentation peaks at 45 and 31 amu. Unfortunately, since it is relatively volatile, it was difficult to tell whether the ethanol peaks detected in the $300 \mathrm{~K}$ residue were weak because little ethanol is made or because most of it is sublimed away at temperatures below $300 \mathrm{~K}$. The appearance of infrared absorption bands consistent with ethanol in the spectra of our residues at $200 \mathrm{~K}(\$ 3.2 .1)$ and weakness of the ethanol peaks in the GC-MS spectra of our $300 \mathrm{~K}$ residues suggests that much of the ethanol is lost during warm up from 200 to $300 \mathrm{~K}$.

Since the production of interstellar ethanol is of current astrophysical interest (Charnley et al. 1995), the conditions that influence its production were investigated further. Several experiments were carried out in which we boosted the initial methanol concentration of the standard ice by a factor of three, carried out the normal depositions and UV irradiations, and used a $\mathrm{LN}_{2}$-cooled glass manifold attached to the sample chamber to capture the residue fraction that evaporated between 200 and $300 \mathrm{~K}$. Comparison of the GC-MS spectra of
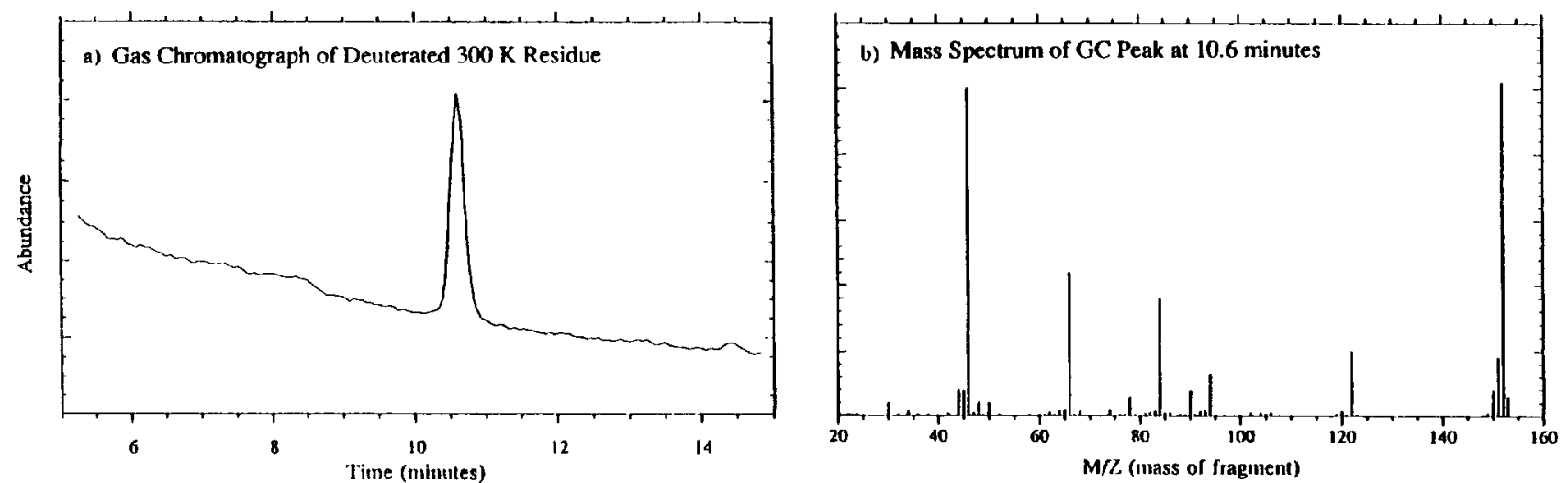

FiG. 5. - (a) Gas chromatograph and (b) mass spectrum of the residue generated from UV photolysis of a $\mathrm{D}_{2} \mathrm{O}: \mathrm{CD}_{3} \mathrm{OD}: \mathrm{CO}: \mathrm{ND}_{3}=100: 50: 10: 10$ mixture that was subsequently warmed to $300 \mathrm{~K}$. The parent mass peak at 152 indicates that fully deuterated HMT was produced upon photolysis and warming. 
this fraction with the GC-MS spectra of pure ethanol vapor (not shown) provided an excellent mass spectral match for peaks with identical retention times of 2.6 minutes, thereby confirming the presence of ethanol $\left(\mathrm{CH}_{3} \mathrm{CH}_{2} \mathrm{OH}\right)$ in the volatile fraction of the residue.

Two additional molecules were identified using GC-MS derivatization techniques (see $\S 2$ ) on the $300 \mathrm{~K}$ residues. These were formamide $\left.\{\mathrm{HC}=\mathrm{O}) \mathrm{NH}_{2}\right\}$ and acetamide $\left\{\mathrm{CH}_{3} \mathrm{C}(=\mathrm{O}) \mathrm{NH}_{2}\right\}$. The retention times and mass spectra of derivatized residues provided excellent matches to those of derivatized standards of both molecules. Presumably, these species are at least partially responsible for the infrared bands seen near 1685 and $1585 \mathrm{~cm}^{-1}(5.93$ and $6.31 \mu \mathrm{m})$ that were assigned to the $\mathrm{C}=\mathrm{O}$ stretching and $\mathrm{H}-\mathrm{N}-\mathrm{H}$ scissoring vibrations, respectively, of amides (see $\$ 3.2 .1$ ).

\subsection{Nuclear Magnetic Resonance}

The production of residues from starting ices in which all the carbon was in the form of ${ }^{13} \mathrm{C}$ made it possible to perform ${ }^{13} \mathrm{C}$ NMR spectroscopy on the resulting $300 \mathrm{~K}$ residues. The NMR spectra of residues produced from $\mathrm{NH}_{3}$-free and $\mathrm{NH}_{3}-$ containing starting mixtures are shown in Figures $6 a$ and $6 b$. These demonstrate that the fraction of the standard astrophysical residue that dissolved readily in $\mathrm{DMSO}-\mathrm{d}_{6}$ (the NMR solvent) is composed of at least three major components. Comparison of the ${ }^{13} \mathrm{C}$ NMR spectrum of the astrophysical residue (Fig. 6b) with that of pure HMT (Fig. $6 d$ ) shows that the carbon resonance at $72 \mathrm{ppm}$ is caused by HMT. Comparison of the residue spectrum (Fig. $6 b$ ) with that of a polyoxymethylene $\left\{\mathrm{POM} ;\left(-\mathrm{CH}_{2}-\mathrm{O}-\right)_{n}\right\}$ standard (Fig. 6c) indicates that the resonance peak at $82 \mathrm{ppm}$ is due to POMlike chemical species. It is evident from the spectra that the residue shows only one POM-type carbon atom, while the standard shows two. This indicates that the standard includes multiple forms of POM (for example, linear, cyclic, and/or branched forms) but the POM-like material in the residues is primarily of one kind. Formation of these two compounds requires the presence of ammonia in the starting materials, in the case of POM synthesis, as a catalyst (Schutte et al. 1993a,b).

Removing ammonia from the starting mixture results in an NMR sample that gives much less signal than a $\mathrm{N}$-containing residue made from a comparable mass of starting materials (Fig. 6a). This is consistent with our observation that the infrared spectrum of the $\mathrm{N}$-free residue exhibits much less infrared extinction. We estimate that the presence of only a few percent of ammonia increases the infrared absorption of the residue by at least a factor of 2. A careful comparison of the NMR spectra in Figures $6 a$ and $6 b$ indicates the main resonance peak near 63 ppm produced by the $\mathrm{N}$-free residue is not due to a new species, but is instead the same peak that shows up strongest in the $\mathrm{N}$-containing residue spectrum (Fig. $6 b$ ). This peak position is characteristic of a carbon bearing a single bond to an oxygen atom, such as in a methoxy $\left(-\mathrm{OCH}_{3}\right)$ group, i.e., carbon atoms bonded to one oxygen atom instead of two as in POMrelated species. This functional group identification is consistent with the carrier being the residue component that gives rise to the infrared absorption peaks at 1345 and $1065 \mathrm{~cm}^{-1}$ $(7.43$ and $9.39 \mu \mathrm{m})$ that dominate the infrared spectrum of the $\mathrm{N}$-free residue (Fig. $2 c$ ). Presumably, some of the absorption at these positions in the infrared spectra of nitrogen-containing residues is also due to this material. Thus, both the IR and NMR spectra suggest a methyl ether, although the infrared data also shows the presence of $\mathrm{OH}$ groups. One possibility,

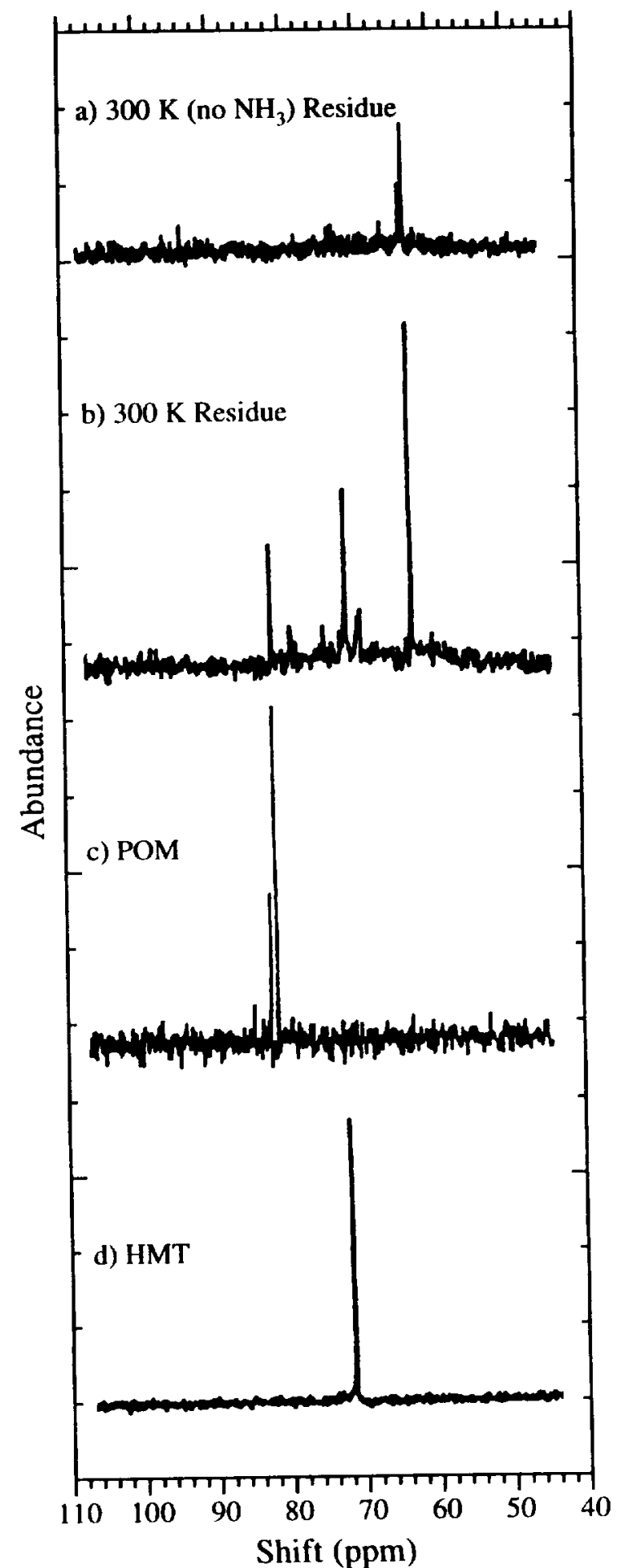

FIG. 6. -40 to $110 \mathrm{ppm}{ }^{13} \mathrm{C}$ NMR spectrum of $(a)$ the residue generated from photolysis of an $\mathrm{H}_{2} \mathrm{O}: \mathrm{CH}_{3} \mathrm{OH}: \mathrm{CO}: \mathrm{NH}_{3}=100: 50: 10: 0$ mixture that was subsequently warmed to $300 \mathrm{~K}$, (b) the residue generated from photolysis of an $\mathrm{H}_{2} \mathrm{O}: \mathrm{CH}_{3} \mathrm{OH}: \mathrm{CO}: \mathrm{NH}_{3}=100: 50: 10: 10$ mixture that was subsequently warmed to $300 \mathrm{~K},(c)$ a sample of pure POM dissolved in $d_{6}$-DMSO, and $(d)$ a sample of pure HMT dissolved in $d_{6}$-DMSO.

therefore, is a nonvolatile methyl ether, such as trimethylorthoformate $\left\{\mathrm{HC}\left(-\mathrm{OCH}_{3}\right)_{3}\right\}$, with small amounts of $\mathrm{H}_{2} \mathrm{O}$ or alcohol impurity. Another possibility is that some of the ether 
molecules have $\mathrm{OH}$ groups in the place of a hydrogen atom, i.e., they are hydroxyl methyl ethers (molecules containing $-\mathrm{OCH}_{2} \mathrm{OH}$ groups), instead of simple methyl ethers (molecules containing $-\mathrm{OCH}_{3}$ groups).

\subsection{Residue Abundances and Production Efficiencies}

The infrared spectra of the starting ices and $300 \mathrm{~K}$ residues can be used to estimate the efficiency with which the various residue components are produced. The column density, $\mathbf{N}$ (in molecules $\mathrm{cm}^{-2}$ ), of a molecule present in the residues can be determined from

$$
N=\frac{\int \tau_{i}(v) d v}{A_{i}} \approx \frac{\left(\tau_{i_{\max }} \Delta v_{i 1 / 2}\right)}{A_{i}},
$$

where $\tau_{f}(v)$ is the frequency-dependent optical depth of a particular absorption band of the molecule $\left[\tau=\ln \left(I_{0} / I\right)\right], \tau_{i}$ is the maximum optical depth of the feature, $\Delta v_{i 1 / 2}$ is the full width at half-maximum (in $\mathrm{cm}^{-1}$ ) of the band in absorbance, and $A_{i}$ is the integrated absorbance (in $\mathrm{cm}$ molecule ${ }^{-1}$ ) of the band. Since the $A_{i}$-values of the bands of HMT have not been previously published in the literature, it was necessary to determine their values before the HMT production efficiency could be calculated. We determined the $A_{i}$ values of HMT in the following way.

First, a carefully measured 200 to 1 mixture of CsI and HMT was thoroughly mixed and formed into a thin disk using standard salt pellet preparation techniques (see Sandford 1984), resulting in a sample with a well determined column density of HMT. The infrared spectrum of the pellet was then obtained and the integrated band areas of the HMT features were measured using standard Nicolet software [i.e., $\int \ln \left\{I_{0}(v) / I(v)\right\} d v$ was measured for each band]. The $A$-values of all the absorption bands of pure, solid HMT given in Table 1 were then calculated using equation (1) $\left[A_{i}=(1 / N) \int \tau_{i}(v) d v\right]$.

The $A$-values of the absorption bands due to HMT in an Ar matrix are also summarized in Table 1 . These values, which should approximate the values for gas phase HMT, were determined in the following way. First, the infrared spectrum of HMT isolated in an argon matrix $(\mathrm{Ar} / \mathrm{HMT} \approx 1000)$ was obtained (Bernstein et al. 1994) and the integrated band areas of the HMT features were measured. We then compared all possible HMT band area ratios from the spectra of both HMT in argon and solid HMT in CsI. Bands that produced ratios that were significantly different between the two spectra are then known to be sensitive to matrix effects, while bands that produce similar ratios are not. The HMT bands near 820 and $670 \mathrm{~cm}^{-1}(12.2$ and $14.9 \mu \mathrm{m})$, and to a lesser extent the $\mathrm{C}-\mathrm{H}$ stretching bands near $2925 \mathrm{~cm}^{-1}(3.42 \mu \mathrm{m})$, all showed significant effects of matrix interactions. In contrast, the remaining four bands provided ratios that all agreed to within a factor of 3 between samples. The bands near 1235 and $1010 \mathrm{~cm}^{-1}(8.10$ and $9.90 \mu \mathrm{m}$ ) provided ratios that agreed to within a factor of 1.5 , indicating matrix interaction effects are smallest for these bands. (Perhaps not surprisingly, both of these bands are associated with $\mathbf{C}-\mathrm{N}$ skeletal vibrations; see Bernstein et al. 1994). We therefore assumed the $A$-value for the band near $1011.2 \mathrm{~cm}^{-1}$ for HMT in Ar is identical to the $A$-value of the $1007.3 \mathrm{~cm}^{-1}$ band for pure HMT in CsI. The $A$ values of the other HMT in Ar bands were then determined by scaling areas with the $1007.3 \mathrm{~cm}^{-1}$ band, i.e., $A_{i}=A_{1007.3} \times\left\{\int \tau_{i}(v) d v /\right.$ $\left.\int \tau_{1007.3}(v) d v\right\}$. Thus, the relative strengths of the $A$-values for HMT in Ar as summarized in Table 1 are expected to be
TABLE 1

The $A$-V Alues of THE Strongest Bands OF HEXAMETHYLENETETRAMINE

\begin{tabular}{|c|c|c|}
\hline $\begin{array}{l}\text { Band Position } \\
\qquad\left(\mathrm{cm}^{-1}\right)\end{array}$ & $\begin{array}{c}\text { Integration } \\
\text { Region } \\
\left(\mathrm{cm}^{-1}\right)\end{array}$ & $\begin{array}{c}\text { Integrated } \\
\text { Absorbance (A) } \\
\text { (cm/molecule) }\end{array}$ \\
\hline \multicolumn{3}{|c|}{ HMT in CsI } \\
\hline $\begin{array}{r}2948.9,2923.9,2874.4 \ldots \ldots \\
1460.7 \ldots \ldots \ldots \ldots \ldots \ldots \ldots \ldots \\
1368.3 \ldots \ldots \ldots \ldots \ldots \ldots \ldots \\
1234.3 \ldots \ldots \ldots \ldots \ldots \ldots \ldots \ldots \\
1007.3 \ldots \ldots \ldots \ldots \ldots \ldots \ldots \ldots \\
815.0 \ldots \ldots \ldots \ldots \ldots \ldots \ldots \ldots \\
670.9 \ldots \ldots \ldots \ldots \ldots \ldots \ldots\end{array}$ & $\begin{array}{c}3000-2825 \\
1468-1450 \\
1385-1360 \\
1246-1228 \\
1020-1000 \\
818-805 \\
677-668\end{array}$ & $\begin{array}{l}2.5 \times 10^{-18} \\
3.8 \times 10^{-19} \\
5.8 \times 10^{-19} \\
2.6 \times 10^{-18} \\
5.0 \times 10^{-18} \\
1.0 \times 10^{-18} \\
9.0 \times 10^{-20}\end{array}$ \\
\hline \multicolumn{3}{|c|}{ HMT in Argon } \\
\hline $\begin{array}{r}2951.6,2922.7,2875.4 \ldots \ldots \\
1458.9 \ldots \ldots \ldots \ldots \ldots \ldots \ldots \ldots \\
1363.0 \ldots \ldots \ldots \ldots \ldots \ldots \ldots \ldots \\
1237.6 \ldots \ldots \ldots \ldots \ldots \ldots \ldots \ldots \\
1011.2 \ldots \ldots \ldots \ldots \ldots \ldots \ldots \ldots \\
819.1 \ldots \ldots \ldots \ldots \ldots \ldots \ldots \ldots \\
669.7 \ldots \ldots \ldots \ldots \ldots \ldots \ldots\end{array}$ & $\begin{array}{c}2988-2850 \\
1465-1456 \\
1368-1358 \\
1243-1233 \\
1015-1007 \\
823-815 \\
675-665\end{array}$ & $\begin{array}{l}7.0 \times 10^{-18 b} \\
7.0 \times 10^{-19} \\
4.7 \times 10^{-19} \\
3.4 \times 10^{-18} \\
5.0 \times 10^{-18 c} \\
5.5 \times 10^{-19} \\
1.3 \times 10^{-18}\end{array}$ \\
\hline
\end{tabular}

- These values were derived assuming the HMT band near $1010 \mathrm{~cm}^{-1}$ has exactly the same $A$-value when isolated in Ar as when in pure form, i.e., matrix interaction effects are ignored. Thus, the relative strengths of the $A$-values for HMT in Ar are expected to be accurate to better than $5 \%$, but their overall absolute strengths could be off by up to a factor of 2 or 3 (see text in $\S 3.5$.).

Broken down for the individual 2951.6, 2922.7, and 2875.4 $\mathrm{cm}^{-1}$ bands, the $A$-values are about $4.2 \times 10^{-18}, 7.0 \times 10^{-19}$, and $2.1 \times 10^{-18} \mathrm{~cm}$ molecule ${ }^{-1}$, respectively.

c Assumed standard value from HMT in CsI (see text in $\$ 3.5$ ).

accurate to better than $5 \%$, but their overall absolute strengths could conceivably be off by a factor as large as 2 .

Armed with these $A$-values, it is possible to estimate the production efficiency of HMT in the photolysis experiments. The column densities of $\mathrm{H}_{2} \mathrm{O}, \mathrm{CH}_{3} \mathrm{OH}, \mathrm{CO}$, and $\mathrm{NH}_{3}$ in the first layer were determined using the single layer column density of methanol as determined using equation (1) for several methanol bands and the known mixing ratios of the components. These were then multiplied by the total number of ice layers in the sample. The starting ice sample used to produce the $300 \mathrm{~K}$ residue spectrum in Figure $1 d$ was deduced to have total column densities of $N_{\mathrm{H}_{2} \mathrm{O}} \approx 3.6 \times 10^{19}$ molecules $\mathrm{cm}^{-2}, \quad N_{\mathrm{CH}_{3} \mathrm{OH}} \approx 1.8 \times 10^{19}$ molecules $\mathrm{cm}^{-2}, \quad N_{\mathrm{CO}} \approx 3.6$ $\times 10^{18}$ molecules $\mathrm{cm}^{-2}$, and $N_{\mathrm{NH}_{3}} \approx 3.6 \times 10^{18}$ molecules $\mathrm{cm}^{-2}$. The amount of HMT in the $300 \mathrm{~K}$ residue of this photolyzed sample was determined by integrating the band areas of all the HMT features in the residue spectrum in Figure $1 d$ and using equation (1) and the $A$-values for HMT in CsI in Table 1. Averaging these estimates for the four HMT bands that show the smallest sensitivity to matrix effects yields an HMT column density of $N_{\mathrm{HMT}} \approx 3.8 \times 10^{17}$ molecules $\mathrm{cm}^{-2}$. Comparing this with the column densities of starting materials demonstrates that the uptake of nitrogen from $\mathrm{NH}_{3}$ into HMT is extremely efficient for this starting mixture and experimental conditions. In this particular example, $\sim 43 \%$ of the total starting $N$ in ammonia ends up in HMT. The uptake of carbon from $\mathrm{CH}_{3} \mathrm{OH}$ into $\mathrm{HMT}$ is also quite efficient, with $\sim 11 \%$ of the total initial $\mathrm{C}$ ending up in HMT in this example (see Table 2). 


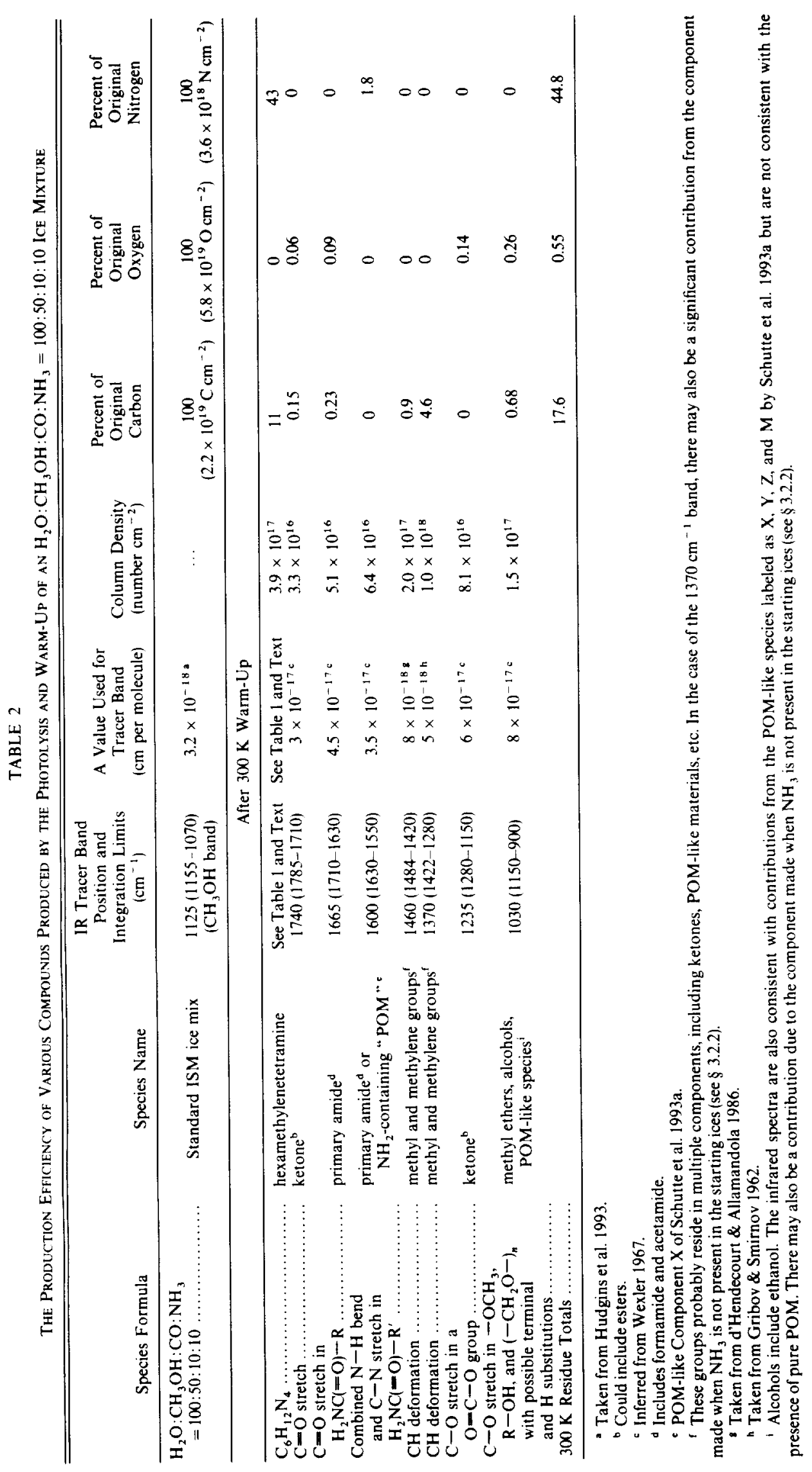


Determining the producton efficiency of the other compounds in the $300 \mathrm{~K}$ residue is more difficult, in part because some of the other components are not fully characterized and in part because many of the other compounds produce overlapping infrared absorption bands. However, a rough approximation can be made simply by adding together the column densities of the various chemical functional groups implied by the different infrared absorption bands. We first assume that the $1740 \mathrm{~cm}^{-1}(5.75 \mu \mathrm{m})$ band is due to a ketone or ester $\mathrm{C}=\mathrm{O}$ stretch, the $1665 \mathrm{~cm}^{-1}(6.01 \mu \mathrm{m})$ band is due to an amide $\mathrm{C}=\mathrm{O}$ stretch, the $1600 \mathrm{~cm}^{-1}(6.25 \mu \mathrm{m})$ band is due to $\mathrm{N}-\mathrm{H}$ scissoring vibrations in $\mathrm{NH}_{2}$ groups, the bands at 1460 and 1370 $\mathrm{cm}^{-1}(6.85$ and $7.30 \mu \mathrm{m})$ are due to $\mathrm{C}-\mathrm{H}$ deformation modes of methyl and methylene $\left(-\mathrm{CH}_{3}\right.$ and $\left.-\mathrm{CH}_{2}-\right)$ groups, the $1235 \mathrm{~cm}^{-1}(8.10 \mu \mathrm{m})$ band is due to the $\mathrm{C}-\mathrm{O}$ stretch in $\mathrm{O}=\mathrm{C}-\mathrm{O}$ groups, and the strong, broad, complex feature extending from 1150 to $900 \mathrm{~cm}^{-1}(8.7-11.1 \mu \mathrm{m})$ is largely due to $\mathrm{C}-\mathrm{O}$ stretching. The band areas of these features and typical $A$-values for these types of vibrations can then be used with equation (1) to derive approximate column densities of the relevant functional groups. A summary of the $A$-values used and the resulting column densities and production efficiencies can be found in Table 2 .

The reader is warned that, for several reasons, the values in Table 2 should only be taken as representative. First, while consistent with our NMR and GC-MS data, the infrared functional group identifications are only tentative. Second, the use of "average" $A$-values for the various functional groups introduces uncertainties that can easily be factors of 2 to 3 and which in some circumstances could conceivably be as large as a factor of 5 . Finally, the values in Table 2 strictly only apply to the conditions explored by this particular experiment. The efficiency of production of these different materials is likely to be a function of starting composition and UV exposure. Preliminary experiments in a new study series in which we are photolyzing each ice layer for only about 30 minutes $(\sim 1 / 20$ the time for the experiments reported in detail here) indicate that these lower UV exposures produce the same components as higher exposure, but that the relative abundances of the various molecular types differ. In particular, lower UV doses seem to produce more amides and less HMT and POMrelated species. This is not surprising since the formation of more complex molecules like HMT and POM is obviously a multiphoton process.

Despite these uncertainties, the results summarized in Table 2 make some important points. First, the majority of the $300 \mathrm{~K}$ residue can be accounted for with only a few main types of material. In order of decreasing relative abundance these are HMT, ethers and POM-related compounds, and ketones and amides. Second, the overall conversion of $\mathrm{C}$ and $\mathrm{N}$ in the starting ice to refractory residue is reasonably high. In this particular experiment, approximately $\frac{1}{5}$ of the carbon and $\frac{1}{2}$ of the nitrogen in the starting ice ended up in the refractory residue. In contrast, a much smaller fraction of the oxygen is taken up into the residue. This is not surprising given that the biggest reservoir of oxygen in the starting ices is in $\mathrm{H}_{2} \mathrm{O}$ and $\mathrm{H}_{2} \mathrm{O}$ is only mildly affected by these UV irradiations (Allamandola et al. 1988). Overall, $\sim 7 \%$ of the $C, N$, and $O$ atoms in the original ice ended up in the $300 \mathrm{~K}$ residue. Making some reasonable assumptions about how the methyl and methylene groups are distributed between all the non-HMT compounds suggests that HMT, ethers and POM-related compounds, and ketones plus amides account for approximately $60 \%, 20 \%$, and
$20 \%$, respectively, of the overall residue in a typical experiment. Finally, we remind the reader that the residue remaining at $300 \mathrm{~K}$ represents only about $20 \%-50 \%$ of the materal present in the $200 \mathrm{~K}$ residue ( $\$ 3.2 .1$ and 3.2.2). This suggests that the vast majority of $\mathrm{C}$ and $\mathrm{N}$ in our starting mixtures was converted into new molecular species.

These results can be compared with those of the previous studies in which ices containing $\mathrm{H}_{2} \mathrm{O}, \mathrm{CH}_{4}, \mathrm{CO}$, and $\mathrm{NH}_{3}$ were photolyzed. Although $\mathrm{CH}_{3} \mathrm{OH}$ was not included in the earlier studies of Agarval et al. (1985) and Schutte (1988), these authors detected molecules similar to those discussed here. However, the efficiency of conversion of icy starting materials into more complex organics in the studies of Hagen et al. (1979) and Schutte (1988) was found to be at least 5 times smaller than that reported here. This difference is understandable in light of the absence of methanol in the earlier studies. The presence of $\mathrm{CH}_{3} \mathrm{OH}$ in our experiments leads to the production of considerably more formaldehyde than occurs in ices that do not contain $\mathrm{CH}_{3} \mathrm{OH}$. Since $\mathrm{H}_{2} \mathrm{CO}$ is directly involved in the formation of $\sim 80 \%$ of the residue that remains at $300 \mathrm{~K}$ in our experiments (HMT and POM-related species), it is not surprising that $\mathrm{CH}_{3} \mathrm{OH}$-containing ices have higher organic conversion efficiencies. An additional consideration is that we estimate that our ices typically received 2 to 3 times the UV dose used in the earlier studies. This presumably also increased the amount of conversion in our experiments.

It is difficult to determine the number of photons needed for the production of any given component (i.e., the effective quantum yield). The quantum efficiency is obviously a function of the initial ice composition (for example, the efficiency of HMT production will be zero in an $\mathrm{NH}_{3}$-free ice, independent of UV dose, see \$3.2.2). In addition, while we know exactly how long each fresh layer of ice was exposed to UV radiation after deposition, it is difficult to quantify how much additional exposure each layer received from subsequent irradiations of overlying layers. Thus, the exact exposure of each ice layer is not known with any certainty. The derived quantum yield is likely to be a function of the total UV exposure. For example, in the lab some photoreactions can reach saturation, that is, they reach a point beyond which additional UV exposure yields diminishing results. For such reactions, continued exposure will not produce any more photoproducts and will result in inferred quantum efficiencies that decrease with increased exposure. In the case of the experiment summarized in Table 2, we obtain an overall "quantum efficiency" of about $0.25 \%$ if we simply compare the total number of new functional groups produced to the total number of UV photons hitting the sample. Given the uncertainties involved, this is not inconsistent with the rough estimate of $1 \%-3 \%$ made for similar experiments reported by Allamandola et al. (1988). It should be pointed out that each ice layer in our experiments typically received on the order of 10 hours of UV exposure. This probably corresponds to the upper limit to UV exposure for ices in typical interstellar clouds.

\subsection{Summary of Results}

During the photolysis of ice mixtures comprised of $\mathrm{H}_{2} \mathrm{O}$, $\mathrm{CH}_{3} \mathrm{OH}, \mathrm{CO}$, and $\mathrm{NH}_{3}$, we observe the formation of carbon monoxide $(\mathrm{CO})$, carbon dioxide $\left(\mathrm{CO}_{2}\right)$, the formyl radical $(\mathrm{HCO})$, formaldehyde $\left(\mathrm{H}_{2} \mathrm{CO}\right)$, methane $\left(\mathrm{CH}_{4}\right)$, and several nitriles (" $\mathrm{XCN}$ " and a probable vinyl cyanide, i.e., a molecule of the form $\mathrm{R}_{2} \mathrm{C}=\mathrm{CH}-\mathrm{CN}$ ). With warming we detect ethanol $\left(\mathrm{CH}_{3} \mathrm{CH}_{2} \mathrm{OH}\right)$, formamide $\left(\mathrm{HC}(=\mathrm{O}) \mathrm{NH}_{2}\right)$, and acetamide 
$\left\{\mathrm{CH}_{3} \mathrm{C}(=\mathrm{O}) \mathrm{NH}_{2}\right\}$. The organic material remaining after photolyzed ice analogs have been warmed to room temperature contains hexamethylenetetramine (HMT; $\mathrm{C}_{6} \mathrm{H}_{12} \mathrm{~N}_{4}$ ), a form (or forms) of polymerized formaldehyde (POM; $\left[-\mathrm{CH}_{2}-\mathrm{O}-\right]_{n}$ ), and other (unidentified) organic materials that probably include ketones, amides, a methyl ether, and alcohols. In order of decreasing relative abundances, a typical $300 \mathrm{~K}$ residue contains about $60 \%$ HMT, $20 \%$ ethers and POM-related compounds, and $20 \%$ ketones and amides. Typically about $\frac{1}{5}$ of the carbon and $\frac{1}{2}$ of the nitrogen in the starting ice ended up in the $300 \mathrm{~K}$ residue and overall, about $10 \%$ of the $\mathrm{C}, \mathrm{N}$, and $\mathrm{O}$ atoms in the original ice ended up in this residue. The organic residues remaining at $300 \mathrm{~K}$ represent only about $20 \%-50 \%$ of the material present at $200 \mathrm{~K}$, suggesting that most of the $\mathrm{C}$ and $\mathrm{N}$ in the starting ice are converted to new species during our irradiation and warm up procedure.

\section{DISCUSSION OF RESULTS AND ASTROPHYSICAL IMPLICATIONS}

\subsection{Bond Destruction and Formation}

It is clear from the data presented in the previous section that UV photolysis causes the destruction of bonds in the starting materials and the formation of new bonds. For example, the oxidation of $\mathrm{CH}_{3} \mathrm{OH}$ to $\mathrm{CO}_{2}$ necessitates the breaking of carbon-hydrogen bonds and the formation of new carbonoxygen bonds. We now discuss some of the implications of the kind of bonds and compounds that form at low and elevated temperatures following the photolysis of astrophysically relevant mixed-molecular ices containing methanol and ammonia.

\subsection{1. $\mathrm{C}-\mathrm{O}$ Bond Formation}

It is apparent from the formation of $\mathrm{H}_{2} \mathrm{CO}, \mathrm{CO}$, and $\mathrm{CO}_{2}$ that $\mathrm{UV}$ irradiation of $\mathrm{CH}_{3} \mathrm{OH}$ in the presence of $\mathrm{H}_{2} \mathrm{O}$ causes the destruction of carbon-hydrogen bonds and the formation of new carbon-oxygen bonds. That a series of new carbonoxygen bonds are formed in more complex species is also evident from the observation of polyoxymethylene-like $\left[-\mathrm{CR}_{2}-\mathrm{O}-\right]_{n}$ compounds and unidentified ethers in the 300 $\mathbf{K}$ organic residue. The most straightforward possibility is that the POM-like material observed here is derived from the purely thermal polymerization of formaldehyde molecules upon warming, a process that will occur as long as some ammonia is present (Schutte et al. 1993a, b). The production of pure POM occurs as shown in equation (2).

$$
n \mathrm{H}_{2} \mathrm{C}=\mathrm{O} \rightarrow\left[-\mathrm{CH}_{2}-\mathrm{O}-\right]_{n} \text { Polyoxymethylene (POM) }
$$

However, as shown by Schutte et al. (1993a, b), many of the hydrogen atoms in this material may be replaced by other functional groups like $-\mathrm{OH},-\mathrm{NH}_{2},-\mathrm{CH}_{3}$, and $-\mathrm{OCH}_{3}$. Finally, some new $\mathrm{C}-\mathrm{O}$ bonds may form by the addition of radicals produced by photolysis, such as $\mathrm{CH}_{3} ; \mathrm{CH}_{3} \mathrm{O} \cdot \mathrm{NH}_{2}$; etc., to $\mathrm{C}=\mathrm{O}$ bonds in photoproducts such as formaldehyde.

For example, the addition of a methyl radical to an oxygen in $\mathrm{CO}_{2}$ leaves the unpaired electron on the carbon, where the most likely result is tht it would find a hydrogen atom, yielding the methyl ester of formic acid (eq. [3]). (The addition of a second methyl group could produce dimethoxymethane, $\mathrm{CH}_{3} \mathrm{O}-\mathrm{CH}_{2}-\mathrm{OCH}_{3}$, the smallest polyether, a truncated version of $\mathrm{POM}$ ).

$$
\mathrm{CH}_{3} \cdot+\mathrm{O}=\mathrm{C}=\mathrm{O} \rightarrow \mathrm{CH}_{3} \mathrm{OC} \stackrel{\text { O }}{\stackrel{+\mathrm{H} \cdot}{\longrightarrow}} \mathrm{CH}_{3} \mathrm{OC}
$$

By analogy one might expect that the same process would apply to the addition of the methyl radical to formaldehyde to produce dimethyl ether (eq. [4]).

$$
\begin{gathered}
\mathrm{CH}_{3}+\mathrm{O}^{-} \mathrm{CH}_{2} \rightarrow \mathrm{CH}_{3} \mathrm{OCH}_{2} \stackrel{+\mathrm{H}}{\longrightarrow} \mathrm{CH}_{3} \mathrm{OCH}_{3} \\
\text { 4.1.2. } \mathrm{C}-\mathrm{N} \text { Bond Formation }
\end{gathered}
$$

The appearance of a new band at $1240 \mathrm{~cm}^{-1}(8.06 \mu \mathrm{m})$ and a prominent shoulder at $1010 \mathrm{~cm}^{-1}(9.90 \mu \mathrm{m})$ in Figure 7 indicate that new carbon-nitrogen single bonds are formed by 40 $\mathrm{K}$. While these peaks correspond nicely with those of HMT (Fig. 7), they may also be caused by its probable precursor, hexahydro 1,3,5-triazine, or a polyaminomethylene (PAM; $\left[-\mathrm{CH}_{2}-\mathrm{NH}-\right]_{n}$ ) (see eq. [5]). As was the case for the formation of carbon-oxygen bonds, the carbon-nitrogen bonds in these molecules could form through the addition of radicals to photoproduct $\mathrm{C}=\mathrm{N}$ bonds or, more likely in our view, through thermal oligimerization of the photoproduct methyleneimine $\left(\mathrm{H}_{2} \mathrm{C}=\mathrm{NH}\right)$ in a reaction akin to that of formaldehyde polymerization with $\mathrm{NH}$ replacing oxygen. A common product of formaldehyde oligimerization reactions is the cyclic trimer (1,3,5-trioxane; eq. [6]) and so it would not be surprising if the trimer of methyleneimine (hexahydro 1,3,5-triazine; eq. [5] were formed at low temperature in our ice mixture.

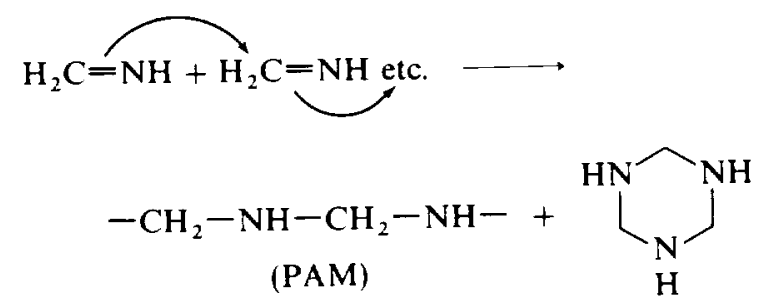

hexahydro 1,3,5-triazine (trimer of methyleneimine)

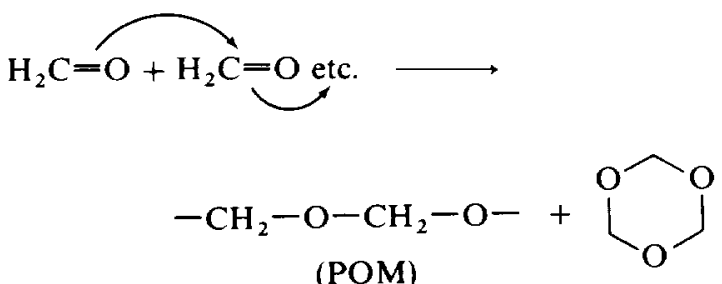

\section{1,3,5-trioxane (trimer of formaldhyde)}

Unlike the formaldehyde trimer, which is stable, the trimer of methyleneimine is not stable and does not persist in this form. This may continue to react with formaldehyde, as seen in Figure 8, ultimately forming hexamethylenetetramine (HMT).

In solutions of $\mathrm{NH}_{3}$ and $\mathrm{H}_{2} \mathrm{CO}$ in liquid $\mathrm{H}_{2} \mathrm{O}, \mathrm{HMT}$ is known to form through the mechanism depicted in Figure 8 (Smolin \& Rapoport 1959; Walker 1964). In our case the formaldehyde comes from the oxidation of methanol by $U V$ radiation with loss of $\mathrm{H}_{2}$ (Sandford \& Allamandola 1993b). In solution, ammonia and formaldehyde are in equilibrium with methyleneimine $\left(\mathrm{H}_{2} \mathrm{C}=\mathrm{NH}\right)$ (Fig. $8 a$ ). This imine of formalde- 


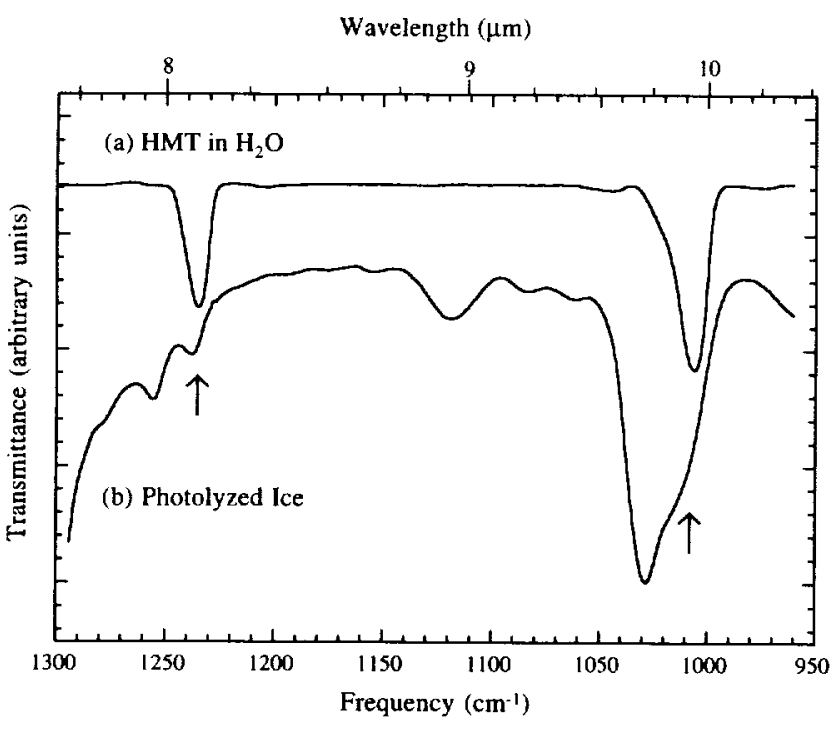

FIG. 7.-1300-950 $\mathrm{cm}^{-1}(7.69-10.5 \mu \mathrm{m})$ infrared spectrum of $(a)$ a sample of pure HMT frozen in $\mathrm{H}_{2} \mathrm{O}$ at $12 \mathrm{~K}$ and subsequently warmed to $40 \mathrm{~K}$ compared to $(b)$ an $\mathrm{H}_{2} \mathrm{O}: \mathrm{CH}_{3} \mathrm{OH}: \mathrm{CO}: \mathrm{NH}_{3}=100: 50: 10: 10$ ice mixture after UV photolysis and warming to $40 \mathrm{~K}$. Arrows indicate the new features produced. This comparison indicates that some HMT or closely related material is produced during photolysis and warm up to $40 \mathrm{~K}$.

hyde is in equilibrium with its trimer, hexahydro 1,3,5-triazine (Fig. $8 b$ ), and other species such as linear oligimers $\left[-\mathrm{CH}_{2}-\mathrm{NH}-\right]_{n}$ (PAM, eq. [5]). The hexahydrotriazine is, in the presence of additional formaldehyde, in equilibrium with 1,3,5-trihydroxymethyl hexahydro 1,3,5-triazine (Fig. 8c). It is interesting to note that all the intermediates formed so far are in equilibrium with one another, ammonia, and formaldehyde. Finally the 1,3,5-trihydroxymethyl hexahydro 1,3,5-triazine can react, irreversibly, with a final molecule of ammonia to produce HMT.

\subsubsection{C-C Bond Formation}

While none of the major components identified in the $300 \mathrm{~K}$ residues contain new carbon-carbon bonds, the detection of small amounts of ethanol $\left(\mathrm{CH}_{3} \mathrm{CH}_{2} \mathrm{OH}\right)$ indicates that this type of bond is also formed during the photolysis and warm up process. Since much of the ethanol made in these experiments is probably lost at temperatures below $300 \mathrm{~K}$ (see $\$ 3.3$ ), the formation of new $\mathrm{C}-\mathrm{C}$ bonds may occur with considerably higher efficiency than is implied solely by the materials remaining at $300 \mathrm{~K}$. The formation of ethanol in the irradiated ices represents an example of a chemical process that can potentially lead to the formation of new molecules containing multiple carbon-carbon bonds and shows that carbon-carbon bonds can be made at low temperatures, either by reactions of " hot" radicals formed by photolysis at $12 \mathrm{~K}$ with neighboring species, or later with cold radicals that are mobilized as the temperature increases during warm up.

While there are many pathways to make ethanol, one possibility is that the methyl radical could add to the carbon of a $\mathrm{C}=\mathrm{O}$ bond in a molecule such as formaldehyde, leaving the unpaired electron on the oxygen where the most likely result is that it will find a hydrogen atom, thereby producing ethanol (eq. [7]).

$$
\mathrm{CH}_{3} \cdot+\mathrm{CH}_{2}=\mathrm{O} \rightarrow \mathrm{CH}_{3} \mathrm{CH}_{2} \mathrm{O} \cdot \stackrel{+\mathrm{H}^{\cdot}}{\longrightarrow} \mathrm{CH}_{3} \mathrm{CH}_{2} \mathrm{OH}
$$

Clearly the addition of the methyl radical to the carbon of $\mathrm{CO}$ or $\mathrm{CO}_{2}$ would proceed in a similar fashion, producing acetaldehyde (ethanal) and acetic acid, respectively (eqs. [8] and [9]).

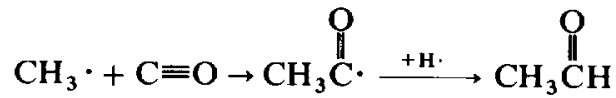

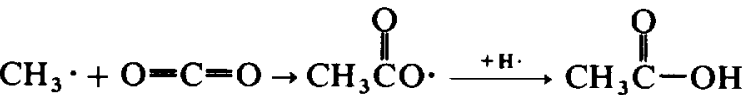

By analogy one might expect that the same kind of process would apply to the addition of the methyl radical to carbonnitrogen double and triple bonds. For example, the addition of the methyl radical to the carbon of methyleneimine (which we suspect is present based on the abundance of HMT and its production mechanism) would produce ethylamine (eq. [10]).

$$
\mathrm{CH}_{3} \cdot+\mathrm{CH}_{2}=\mathrm{NH} \rightarrow \mathrm{CH}_{3} \mathrm{CH}_{2} \dot{\mathrm{NH}} \stackrel{+\mathrm{H} \cdot}{\longrightarrow} \mathrm{CH}_{3} \mathrm{CH}_{2} \mathrm{NH}_{2}
$$

\subsubsection{Photoproducts versus Thermal Products}

One of the most remarkable aspects of this work is the fact that the chemical composition of the residue produced by photolysis of the $\mathrm{H}_{2} \mathrm{O}: \mathrm{CH}_{3} \mathrm{OH}: \mathrm{CO}: \mathrm{NH}_{3}=100: 50: 10: 10$ interstellar ice analog is considerably different from the residues produced by the purely thermal warm up of ices composed of an appropriate mixture of the $\mathrm{H}_{2} \mathrm{O}: \mathrm{CH}_{3} \mathrm{OH}: \mathrm{CO}: \mathrm{NH}_{3}$ starting material plus their major photoproducts. For example, the warm up of an unphotolyzed $\mathrm{H}_{2} \mathrm{O}: \mathrm{CH}_{3} \mathrm{OH}: \mathrm{H}_{2} \mathrm{CO}: \mathrm{CH}_{4}$ : $\mathrm{CO}_{2}: \mathrm{CO}: \mathrm{NH}_{3}: \mathrm{O}_{2}=100: 20: 4.0: 0.5: 0.35: 3.5: 0.8: 10$ ice, a mixture that provides a good match to the spectrum of an irradiated $\mathrm{H}_{2} \mathrm{O}: \mathrm{CH}_{3} \mathrm{OH}: \mathrm{CO}: \mathrm{NH}_{3}$ ice, yields a residue which is dominated by a variety of polyoxymethylene-like compounds produced by the polymerization of $\mathrm{H}_{2} \mathrm{CO}$ with itself and other species in the ice catalyzed by trace amounts of $\mathrm{NH}_{3}$ (Schutte et al. 1993a, b). While these compounds may be similar (or even identical) to the POM-like fraction detected in the photolysis residues by ${ }^{13} \mathrm{C} N \mathrm{NMR}$, it is interesting that the purely thermal experiments of Schutte et al. showed absolutely no infrared spectral evidence for the production of HMT, while the photolysis experiments produce HMT as a major component. This is surprising given that $\mathrm{H}_{2} \mathrm{O}$ and $\mathrm{NH}_{3}$ are known to react in the gas phase at room temperature principally forming HMT (Smolin \& Rapoport 1959; Walker 1964). Furthermore, there was little evidence for ketones, esters, or amides in the thermal experiments, while they are relatively abundant in the UV irradiation residues.

These differences in HMT production imply that the key chemical reaction steps involve an "activation barrier" which UV photons can help overcome. In the absence of UV photons, the available thermal energy may be insufficient to surmount this barrier and the $\mathrm{H}_{2} \mathrm{CO}$ may instead be converted into POM-like compounds via reactions having low activation barriers in the solid state at low temperatures (Schutte et al. $1993 \mathrm{a}, \mathrm{b})$. It's possible that the methyleneimine production shown in the second step of reaction $A$ in Figure 8 is induced by the photofragmentation of either $\mathrm{H}_{2} \mathrm{CO}$ or $\mathrm{NH}_{3}$, which produces an appropriate intermediate species that drives methyleneimine production. Indeed, photons could potentially play an important role at low temperatures in many of the reaction steps shown in Figure 8 . Similarly, while we have discussed HMT as a specific example, the general principle may apply to the chemistry that produces the other species (ketones, amides, etc.) that are not seen in residues produced solely by thermal warm up. 


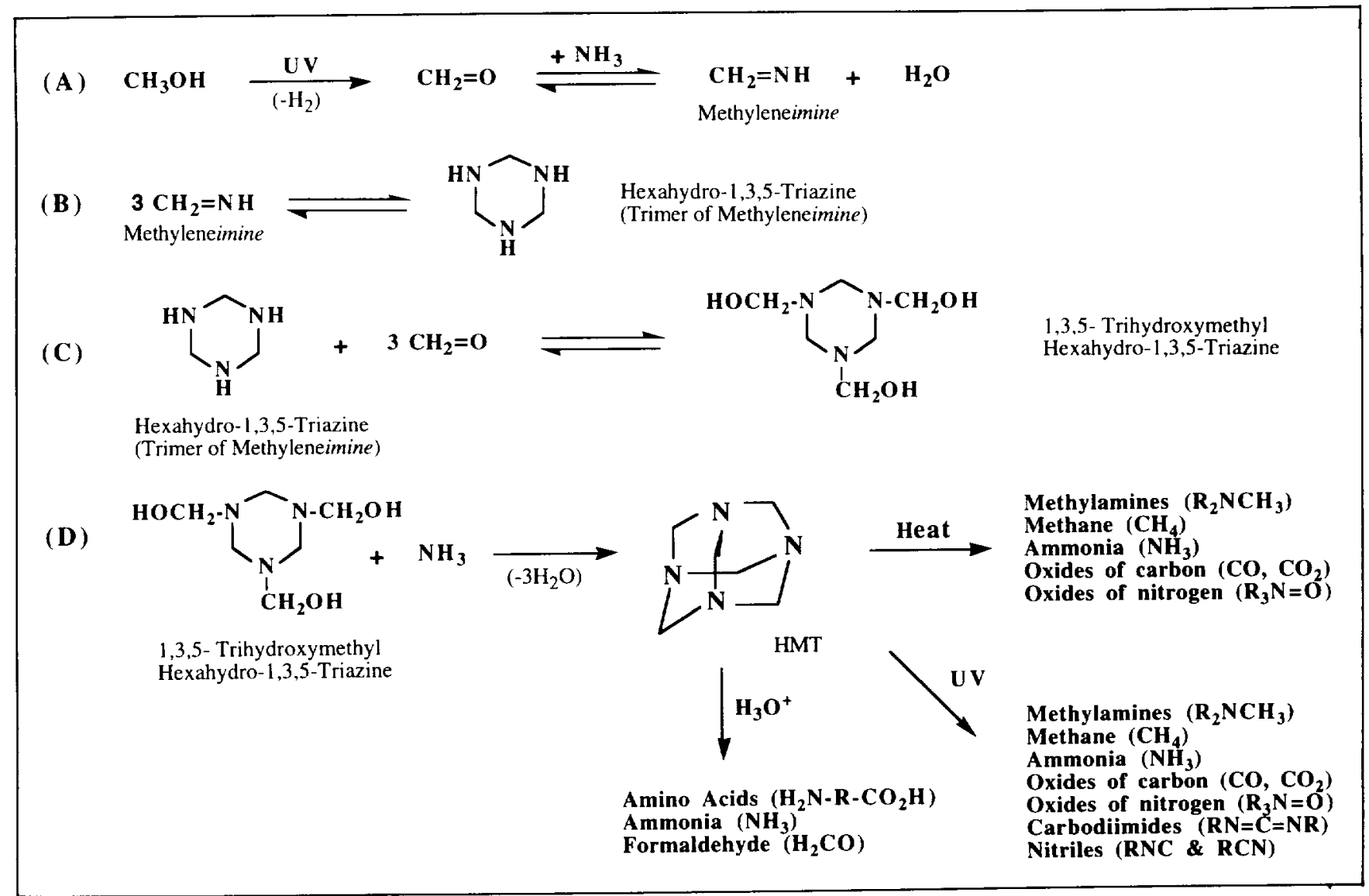

FIG. 8. (a) Production of methyleneimine. (b)-(d) The chemical mechanism by which HMT is known to form in solution from methyleneimine and some of the products resulting from the destruction of HMT under various conditions.

\subsection{HMT and Its Astrophysical Implications}

In $\S 3.5$ it was shown that HMT, which contains four nitrogens per molecule, comprises a significant portion $(\sim 60 \%)$ of the $300 \mathrm{~K}$ organic residue produced by photolysis (Fig. 4 and Table 2). While ammonia (the sole nitrogen-containing reactant) represents less than $5 \%$ of the starting mixture, the high efficiency of nitrogen incorporation into HMT $(40 \%$ $50 \%$ ) allows for substantial HMT production and is the main $\mathrm{NH}_{3}$ sink. This high efficiency of nitrogen conversion from ammonia into HMT, in conjunction with the central role $\mathrm{NH}_{3}$ plays in thermal formaldehyde polymerization reactions, may account for the difficulty astronomers have had in detecting the infrared bands of frozen $\mathrm{NH}_{3}$ in cold clouds (see Knacke et al. 1982). The lack of a solid $\mathrm{NH}_{3}$ detection has been difficult to account for satisfactorily since it is among the most abundant polyatomic species known to be present in the gas phase (see Mauersberger et al. 1992) and it should efficiently condense into interstellar ices (Sandford \& Allamandola 1993a). These experiments suggest that HMT may comprise a significant portion of the organic material in interstellar ice grains and their thermal residues and may account for a substantial fraction of the solid state nitrogen inventory. Insofar as these materials survive and are incorporated into forming stellar systems, they may make up a significant fraction of the organics in comets and icy planetesimals. Indeed, the presence of HMT has been suggested as an explanation of the very low abundance of $\mathrm{NH}_{3}$ in Comet Halley (Kargel 1992). Thus, it is quite possible that substantial amounts of HMT was delivered to the early Earth by accreted dust and larger impactors.

Interest in this molecule is not new. HMT has been known to the chemistry community for over 130 years (Bulterov 1859), and it was suggested it might be a component of interstellar grains over 20 years ago when it was noticed that HMT formed spontaneously at room temperature when pure ammonia and formaldehyde were mixed (Sagan \& Khare 1970; Khare \& Sagan 1973). HMT has been detected as a minor component in the residues produced by the photolysis of nonmethanol containing interstellar ice analogs (Briggs et al. 1992). (The dominance of HMT in our experiments appears to be a direct result of the substantial amounts of methanol in our starting mixtures.) Furthermore, hydrolysis of HMT by concentrated acid has been shown to yield amino acids (Wolman et al. 1971). This raises the very intriguing possibility that amino acids could have been produced in planetesimals and on the early earth by the hydrolysis of HMT produced in the interstellar medium.

\subsubsection{Destruction of HMT}

Having shown how interstellar processes can make HMT, it is reasonable to examine its likely fate. While some HMT may endure and could potentially be identified by infrared spectroscopy, much of it may be destroyed by the ambient radiation of the ISM or conditions on any body in which it might be incorporated. The lower right corner of Figure 8 outlines some 
of the products that have been experimentally reported to result from the destruction of HMT under various conditions. Methyl amines, methane, ammonia, oxides of carbon and nitrogen, carbodiimides ( $R N=C=N R$ ) and isonitriles and nitriles ( $R-N \equiv C$ and $R-C \equiv N$, respectively) are formed in the UV photolysis of HMT under astrophysical conditions (Bernstein et al. 1994). Similarly, methyl amines, methane, ammonia, and oxides of carbon and nitrogen are the volatile products of thermolysis of HMT in a flowing tube reactor (Iwakami, Takazono, \& Tsuchiya 1968). Interestingly, amino acids, ammonia, and formaldehyde are known products of the hydrolysis of HMT with concentrated acid (Wolman et al. 1971). We are currently carrying out a study to determine whether the hydrolysis of HMT in the less acidic solutions characteristic of the hydrothermal events that occurred on some meteorite parent bodies can also produce these compounds.

\subsubsection{The Connection of HMT to the Carrier of the "XCN" Feature}

In 1979, Soifer et al. reported the detection of a relatively weak absorption feature near $2170 \mathrm{~cm}^{-1}(4.61 \mu \mathrm{m})$ in the spectrum of the bright compact infrared source W33A. They tentatively identified the source of this feature as solid CO. Lacy et al. (1984) subsequently obtained higher resolution spectra of this object (and six others) and determined that the feature reported by Soifer et al. could be resolved into several separate absorption bands. A band near $2140 \mathrm{~cm}^{-1}(4.67 \mu \mathrm{m})$ was shown to be due to solid $\mathrm{CO}$ frozen into icy grain mantles having several different compositions (Lacy et al. 1984; Sandford et al. 1988; Tielens et al. 1991).

In addition to the solid $\mathrm{CO}$ feature, Lacy et al. also detected a broader feature centered near $2160 \mathrm{~cm}^{-1}(4.63 \mu \mathrm{m})$ (Fig. $9 a$ ). After an extensive series of laboratory studies in which a number of ice samples were examined, it was suggested that the feature was produced by $C \equiv N$ stretching vibrations in an unidentified nitrile $(X-C \equiv N)$ or isonitrile $(X-N \equiv C)$. Several

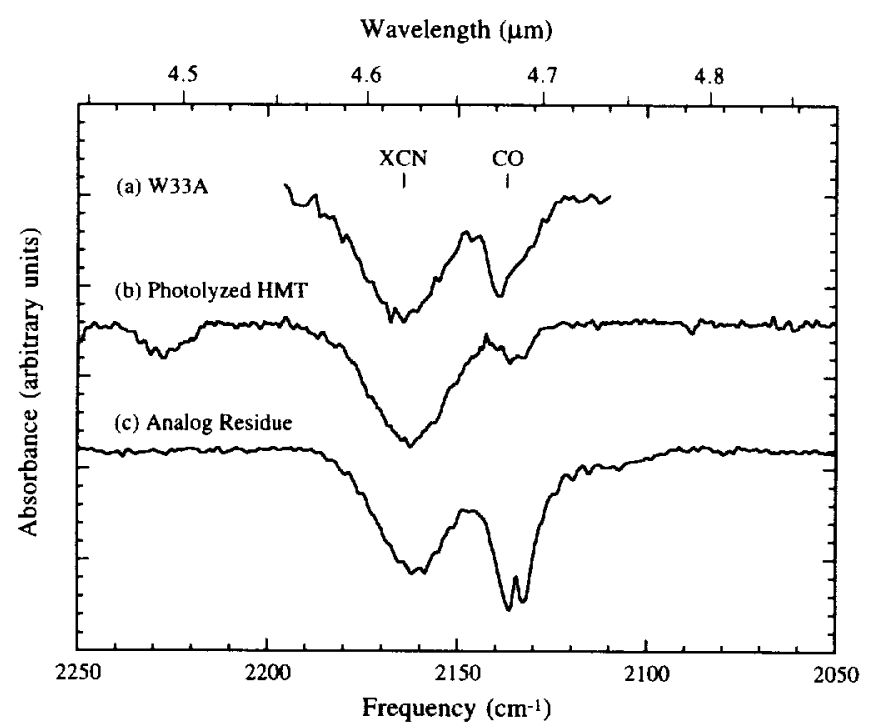

Fig. 9. - 2250-2050 $\mathrm{cm}^{-1}(4.44-4.88 \mu \mathrm{m})$ infrared spectrum of $(a)$ W $33 \mathrm{~A}$, a protostar deeply embedded in an interstellar cloud of dust, gas, and ice (see Lacy et al. 1984), (b) HMT photolyzed in $\mathrm{H}_{2} \mathrm{O}\left(\mathrm{H}_{2} \mathrm{O} / \mathrm{HMT} \approx 3\right)$ at $12 \mathrm{~K}$ and subsequently warmed to $150 \mathrm{~K}$ (taken from Bernstein et al. 1994), and (c) the residue produced when an $\mathrm{H}_{2} \mathrm{O}: \mathrm{CH}_{3} \mathrm{OH}: \mathrm{CO}: \mathrm{NH}_{3}=100: 50: 10: 10$ ice is photolyzed at $12 \mathrm{~K}$ and subsequently warmed to $150 \mathrm{~K}$. possible structures have been suggested for the carrier (d'Hendecourt \& Allamandola 1986), but the exact identity of this species is still unknown and the carrier is usually referred to as $\mathrm{XCN}$ or $\mathrm{X}(\mathrm{C} \equiv N)$. Alternative identifications for this band have been suggested, namely the $\mathrm{CN}$ stretch in the ion $\mathrm{OCN}^{-}$(Grim \& Greenberg 1987) and the SiH stretching vibration (Nuth \& Moore 1988; Moore, Tanabé, \& Nuth 1991), although these identifications seem to be inconsistent with various aspects of the physical and spectral properties of the carrier (Tegler et al. 1993).

To date, the best spectral matches to the $2160 \mathrm{~cm}^{-1} \mathrm{XCN}$ feature have been provided by astrophysically relevant ice samples containing $\mathrm{H}_{2} \mathrm{O}, \mathrm{CH}_{3} \mathrm{OH}, \mathrm{CO}$, and $\mathrm{NH}_{3}$ that are irradiated with UV photons and subsequently warmed (Allamandola et al. 1988; Tegler et al. 1993). Since these very same ices and processes produce HMT, and HMT contains an abundance of $\mathrm{C}-\mathrm{N}$ bonds, it is reasonable to consider the possibility that HMT and the XCN carrier may be in some way related.

To investigate this possibility, the UV photolysis of HMT in $\mathrm{H}_{2} \mathrm{O}$ ices was examined (Bernstein et al. 1994). It was found that the photolysis of $\mathrm{H}_{2} \mathrm{O}: \mathrm{HMT}$ mixtures produces, among other things, a band near $2160 \mathrm{~cm}^{-1}(4.63 \mu \mathrm{m})$ that provides an excellent match to the interstellar XCN feature (Fig. 9). This suggests a relationship between HMT and the carrier of the $\mathrm{XCN}$ feature may exist. At present, it is not clear whether this relationship is "genetic" (i.e., interstellar XCN is made from HMT), or whether the two species are simply involved in the same reaction pathways (i.e., both are made from similar building blocks and the photolysis of HMT breaks it down into component parts that can reassemble to produce some $\mathrm{XCN}$ ). We are currently carrying out experiments to answer this question and the identification of XCN and other volatiles will be discussed in a separate publication.

\subsection{3. $\mathrm{HMT}$ and $\mathrm{XCN}$ in Comets}

Since comets may consist of aggregated interstellar materials, it is worth considering what implications the presence of XCN and HMT might have for cometary chemistry and activity. One of the earliest species identified in cometary comae was the cyanide radical ( $\mathrm{CN} \cdot$ ), which was identified on the basis of a strong group of emission bands observed in the violet portion of the visible spectrum (see Arpigny 1965 for a discussion of the spectroscopy of cometary CN). Despite being one of the first compounds detected in comets, the source of the $\mathrm{CN}$ remains unidentified. In fact, there are indications that there may be more than one source of $\mathrm{CN}$ (Klavetter \& A'Hearn 1994). Studies of the scale length of $\mathrm{CN}$ in the comae of comets indicate that it is probably not derived directly from the cometary nucleus. Instead, it appears that $\mathrm{CN}$ is injected into the gas phase in cometary comae either via sublimation from escaping grains or as a consequence of the photodestruction of larger parent molecules. In either case, the scale height of the $\mathrm{CN}$ is probably a function of the volatility and UV cross section of the parent molecule(s).

It is interesting to consider the possibility that XCN and HMT may be among the parent molecules of cometary $\mathrm{CN}$ and related species. It has previously been noted that the carrier of the XCN feature sublimes rapidly at temperatures around $250 \mathrm{~K}$, indicating a volatility that is within the range expected of the parent molecule for cometary $\mathrm{CN}$ (Allamandola et al. 1988). HMT is more refractory than XCN and therefore seems less likely to be a direct parent of cometary 
$\mathrm{CN}$. However, as was noted in the previous section, the photolysis of HMT produces XCN, so HMT could possibly be a "grandparent" of cometary $\mathrm{CN}$. It has been noted that the scale heights of both $\mathrm{CO}$ and $\mathrm{CN}$ in cometary comae are similar (see Klavetter \& A'Hearn 1994). Klavetter and A'Hearn suggest this match might imply that the $\mathrm{CO}$ and $\mathrm{CN}$ are produced by the photodestruction of $\mathrm{H}_{2} \mathrm{CO}$ and $\mathrm{HCN}$, which are in turn produced from "tholins" that vaporize just inside $10,000 \mathrm{~km}$ of the nucleus. We would suggest that a similar process, but instead involving XCN and HMT, offers an attractive alternative since there is a clear evidence for $\mathrm{XCN}$ in the interstellar medium. Clearly, some additional observational and theoretical consideration of XCN and HMT as parents of cometary $\mathrm{CN}$ is merited.

Observationally, this possibility might be addressed by searching for the characteristic infrared features of HMT (see Table 1) in the spectra of comets. Such a search would be difficult since HMT would be expected to constitute only a fraction of the $\mathrm{C}$-containing species present and its strongest band simultaneously falls in a region partially obscured by telluric ozone, is superposed on the $\mathrm{Si}-\mathrm{O}$ silicate band, and will overlap any $\mathrm{C}-\mathrm{O}$ bands present.

It is interesting to note that recent studies of the $\mathrm{C}-\mathrm{H}$ stretching emission features of gas phase $\mathrm{CH}_{3} \mathrm{OH}$ in cometary comae indicate that there is an additional emission component underlying the previously identified methanol features (see Hoban et al. 1993). When the emission contributions due to methanol are removed, the remaining emission feature falls at a position that is characteristic of materials rich in $-\mathrm{CH}_{2}-$ groups. All the carbon in $\mathrm{HMT}$ is in $-\mathrm{CH}_{2}-$ groups. More rigorous comparisons between HMT and cometary spectra should become possible as higher quality cometary spectra in the $\mathrm{C}-\mathrm{H}$ stretching region become available (DiSanti et al. 1995). Furthermore, a potential emission feature has been detected near $815 \mathrm{~cm}^{-1}(12.2 \mu \mathrm{m})$ in the spectrum of Comet Wilson (see Hanner, Lynch, \& Russell 1994) which has a very similar position and width one of the stronger HMT bands. However, this feature appears to be rare in comets (at least as a well-defined feature) and it is not clear if the other strong HMT bands are present in the Comet Wilson spectrum. Thus, there is presently no direct spectral evidence for HMT in comets. A search for the spectral features of HMT in future high quality cometary infrared spectra would clearly be of interest.

\subsection{Astrophysical Implications of Other Residue Components}

The detection of $\mathrm{CH}_{3} \mathrm{CH}_{2} \mathrm{OH}$ (ethanol), $\mathrm{HC}(=\mathrm{O}) \mathrm{NH}_{2}$ (formamide), $\quad \mathrm{CH}_{3} \mathrm{C}(=\mathrm{O}) \mathrm{NH}_{2}$ (acetamide), ketones $\left\{\mathrm{R}-\mathrm{C}(=\mathrm{O})-\mathbf{R}^{\prime}\right\}$, and compounds related to polyoxymethylene $\left\{\mathrm{POM},\left(-\mathrm{CH}_{2} \mathrm{O}-\right)_{n}\right\}$ in the photolysis residues, as well as the detection of similar compounds in other ice analog experiments (Agarwal et al. 1985; Briggs et al. 1992; Schutte et al. 1993a, b), suggests that these species may be present in interstellar and cometary ices. The presence of these classes of molecules in interstellar and cometary dust could potentially be confirmed by searching for the characteristic infrared bands produced by these materials (see $\S 3.2$ ). Some of these molecules have already been detected in small amounts in the gas phase in the ISM using radio techniques (see Irvine, Goldsmith, \& Hjalmarson 1987).

Of the new materials produced in our experiments, the ethanol and POM-related species are of particular current interest. Interstellar medium ethanol has been detected in the gas phase in dense molecular clouds using radio techniques (see Zuckerman et al. 1975; Millar et al. 1988; Turner 1991).
Theoretical gas-phase chemistry models have explored chemical pathways by which ethanol can be produced and it has become apparent that gas phase reactions are insufficient to produce the amounts observed. As a result, it has been suggested that a solid state origin is implied (Charnley, Tielens, \& Millar 1992; Charnley et al. 1995), i.e., the ethanol is produced in the solid phase and then liberated into the gas phase when interstellar ice grains are warmed or destroyed. Our results indicate that this possibility merits serious consideration. Whether the production of ethanol by the UV photolysis of ices is efficient enough to explain the observed gas phase abundances is not clear since our GC-MS detection of ethanol does not provide information about relative or absolute abundances in the residues. Determining the efficiency of ethanol production is clearly an important issue for the future.

The presence of POM-like species in the photolysis residues supports the possibility that such species are present in cometary and interstellar organics. Based on data obtained by the Giotto spacecraft, it has been suggested that POM was present in the coma of Comet p-Halley (Huebner 1987; Huebner, Boice, \& Sharp 1987) although this identification has been questioned (Mitchell et al. 1992). The RPA2-Positive Ion Cluster Composition Analyzer (PICCA) instrument detected five distinct groups of mass abundance peaks with regular spacings of 15 amu which started at $45 \mathrm{amu}$ and decreased in intensity with increasing mass. Such a distribution of peaks is consistent with the dissociation products of the formaldehyde polymer polyoxymethylene. We have shown here that POMlike materials are made during the photolysis and warm up of realistic interstellar/cometary ice analogs. In addition, it has already been demonstrated that a variety of POM-like components are produced by purely thermal processes when formaldehyde is warmed in the presence of $\mathrm{H}_{2} \mathrm{O}, \mathrm{CH}_{3} \mathrm{OH}$, and $\mathrm{NH}_{3}$ (Schutte et al. 1993a, b). Thus, POM-like materials could find their way into comets by a variety of processes, although the exact nature of the POM will likely be dependent on the composition of the starting ice and its radiation history. It should be stressed, however, that none of these processes produces significant amounts of the pure "classical " form of polymeric POM, $\left(-\mathrm{CH}_{2} \mathrm{O}-\right)_{n}$, in astrophysically relevant ices. Instead, the species produced seem to correspond to POM-like structures in which some of the $\mathrm{H}$ atoms and terminal groups are replaced by $-\mathrm{OH},-\mathrm{NH}_{2}$, and other chemical functional groups.

\subsection{Energy Sources}

The formation of formaldehyde by the photolysis of methanol is clearly of great importance since it is the building block of larger molecules such as POM and HMT. It has been suggested that acetone is produced in preference to formaldehyde in similar experiments where ions (to simulate cosmic rays) are used in place of UV photons as a source of energy (G. Strazzulla 1994, private communication). Since the formation of HMT depends on formaldehyde, the suite of organic molecules that stem from cosmic ray irradiation could differ from those forming as a result of UV radiation. One consequence of ion production of acetone in place of formaldehyde is that HMT should not be produced since the imine of acetone would form in place of the imine of formaldehyde.

$$
\begin{aligned}
& \mathrm{H}_{2} \mathrm{C}=\mathrm{O}+\mathrm{NH}_{3} \rightarrow \mathrm{H}_{2} \mathrm{C}=\mathrm{NH} \text { imine of formaldehyde } \\
& \left(\mathrm{CH}_{3}\right)_{2} \mathrm{C}=\mathrm{O}+\mathrm{NH}_{3} \rightarrow\left(\mathrm{CH}_{3}\right)_{2} \mathrm{C}=\mathrm{NH} \text { imine of acetone }
\end{aligned}
$$


In the pathway leading to HMT three imine molecules cyclize to form hexahydro 1,3,5-triazine.<smiles>CNCCCCCN</smiles>

Hexahydro 1,3,5-triazine

(trimer of methyleneimine)

In the case of acetone, however, the three imine molecules would be less likely to react with one another because of severe steric hindrance. If they did react, they would most likely not go on to make the cyclic form seen in equation (14) because, while there are only three axial hydrogen atoms above the triazine ring in the trimer in equation (13), the compound in equation (14) would require squeezing three methyl groups into the same space:

$$
3\left(\mathrm{CH}_{3}\right)_{2} \mathrm{C}=\mathrm{NH} \longrightarrow \mathrm{H}_{3}
$$

Hexahydro 1,3,5-hexamethyl triazine (trimer of the imine of acetone)

Even if such a congested molecule could form, it is highly unlikely that it would go on to capture the other three formaldehydes necessary to form HMT. Given the steric barriers toward making cyclic structures starting with acetone, it is more likely that linear molecules, such as methyl-substituted PAM ([- $\left.\mathrm{C}\left(\mathrm{CH}_{3}\right)_{2}-\mathrm{NH}-\right]_{n}$; eq. [5]), will be favored over ring and cage molecules since the linear form will minimize interactions between the methyl groups.

A very important implication is that the organic molecules that form as a result of ion irradiation, UV irradiation, and thermal processing may be sufficiently different from one another that the relative concentrations of the organics observed in cometary and interstellar ices could be diagnostic of their radiation and thermal histories. Searching for processspecific species during comet rendezvous and analysis missions could significantly improve our understanding of the processes that make and modify comets. HMT may be a unique tracer of photochemical processing. Thus, the detection of significant amounts of HMT on a particular comet would imply that radiation processing was important in the precometary interstellar phase (photolysis will not be a significant source of chemical synthesis once a comet has been formed since photons cannot penetrate the nucleus). In contrast, if substantial amounts of complex organic molecules more characteristic of ion irradiation are detected it would imply that bombardment by cosmic rays, possibly even after comet formation, was important (see Johnson et al. 1986). Alternatively, if POM-like species are found to be more abundant, thermal processing would be implicated as the dominant source of complex organic synthesis. While it is likely that all three processes are important at one time or another in a comet's history, the analyses of species characteristic of each process in cometary nuclei will make it possible to deduce the details of cometary chemical history.

\section{CONCLUSIONS}

We have studied the chemistry that occurs when interstellar/ cometary ice analogs containing $\mathrm{H}_{2} \mathrm{O}, \mathrm{CH}_{3} \mathrm{OH}, \mathrm{CO}$, and $\mathrm{NH}_{3}$ are irradiated with ultraviolet photons at $12 \mathrm{~K}$ and thermally processed. Infrared spectra indicate that UV exposure of these ice analogs results in the production of many new molecular species, largely at the expense of the methanol. The new species produced include $\mathrm{CO}$ (carbon monoxide), $\mathrm{CO}_{2}$ (carbon dioxide), $\mathrm{CH}_{4}$ (methane), $\mathrm{HCO}$ (the formyl radical), $\mathrm{H}_{2} \mathrm{CO}$ (formaldehyde), and several nitriles (" $\mathrm{XCN}$ " and a probable vinyl cyanide, $\mathrm{R}_{2} \mathrm{C}=\mathrm{CH}-\mathrm{C} \equiv \mathrm{N}$ ).

Warming of these ices above $150 \mathrm{~K}$ results in the sublimation loss of most of the starting materials and in the mobilization of radicals and other reactive species in the sample. These participate in further reactions and produce additional molecules. Infrared spectroscopy and gas chromatographymass spectrometry indicate that by a temperature of $200 \mathrm{~K}$, the sample contains $\mathrm{CH}_{3} \mathrm{CH}_{2} \mathrm{OH}$ (ethanol), $\mathrm{HC}(=\mathrm{O}) \mathrm{NH}_{2}$ (formamide), $\mathrm{CH}_{3} \mathrm{C}(=\mathrm{O}) \mathrm{NH}_{2}$ (acetamide), and molecules with $\mathrm{C} \equiv \mathrm{N}$ groups (nitriles). These species may have been produced by photolysis alone, or may have formed during warm up.

A combination of infrared spectroscopy, ${ }^{1} \mathrm{H}$ and ${ }^{13} \mathrm{C}$ nuclear magnetic resonance (NMR) spectroscopy, and gas chromatography-mass spectrometry techniques demonstrate that the organic materials remaining after the photolyzed ice analogs have been warmed to room temperature contain (1) hexamethylenetetramine (HMT, $\mathrm{C}_{6} \mathrm{H}_{12} \mathrm{~N}_{4}$ ), (2) ethers, alcohols, and compounds related to polyoxymethylene (POM, $\left(-\mathrm{CH}_{2} \mathrm{O}-\right)_{n}$ with $\mathrm{H}$ substitutions $\}$, and (3) ketones $\left\{\mathrm{R}-\mathrm{C}(=\mathrm{O})-\mathrm{R}^{\prime}\right\}$ and amides $\left\{\mathrm{H}_{2} \mathrm{NC}(=\mathrm{O})-\mathbf{R}\right\}$. Typically these three groups of components account for approximately $60 \%, 20 \%$, and $20 \%$, respectively, of the $300 \mathrm{~K}$ residue. Most of the carbon in these residues is thought to come from the methanol in the original ices. Deuterium and ${ }^{13} \mathrm{C}$ isotopic labeling demonstrates that methanol is definitely the source of the carbon in HMT.

Typically, about $20 \%$ of the carbon and $50 \%$ of the nitrogen in the starting ice ended up in the $300 \mathrm{~K}$ residue and overall, about $7 \%$ of the $\mathrm{C}, \mathrm{N}$, and $\mathrm{O}$ atoms in the original ice ended up in this fraction. The total infrared absorption produced by the $300 \mathrm{~K}$ fraction is typically only $20 \%-50 \%$ that of the $200 \mathrm{~K}$ residue. This implies that most of the $\mathrm{C}$ and $\mathrm{N}$ in the starting ices are converted to new species during our irradiation and warm up procedure, i.e., few of the $\mathrm{C}$ - and $\mathrm{N}$-containing species in the original ice escape unaltered. In contrast, a much smaller percentage of the $O$ is included in the organic residue at $300 \mathrm{~K}$. While it is difficult to precisely determine the photon "quantum efficiency" of the production of new chemical functional groups in these experiments, values on the order of $1 \%$ were typical, consistent with previously reported values. However, these efficiencies are dependent on ice composition and total UV fluence.

The production of ethanol in the solid state has important astrophysical implications since it has been detected in the gas phase in dense interstellar clouds at concentrations too high to be accounted for soley by gas-phase chemistry. These experiments demonstrate that the ethanol may actually be made in the solid phase and then liberated into the gas phase where it is ultimately observed.

The production of HMT may have even more profound astrophysical implications. Given that HMT is relatively $\mathrm{N}$-rich, its efficient production implies a high efficiency of $\mathrm{N}$ 
incorporation from $\mathrm{NH}_{3}(40 \%-50 \%$ in a typical experiment). This suggests that interstellar HMT may contain a substantial fraction of the nitrogen inventory in interstellar and cometary materials. This may explain, at least in part, past difficulties in detecting solid state $\mathrm{NH}_{3}$ and accounting for the nitrogen inventory in dense interstellar clouds.

HMT is probably formed through a mechanism in which formaldehyde derived from the UV photolysis of methanol reacts with ammonia to form methyleneimine $\left(\mathrm{H}_{2} \mathrm{C}=\mathrm{NH}\right)$. Subsequent reactions involving methyleneimine make intermediaries that ultimately result in the production of HMT. Many of these intermediary species may also be present in interstellar or cometary ices. Additionally, species resulting from the decomposition of HMT may also be present in space. For instance, the photolysis of $\mathrm{HMT}$ in $\mathrm{H}_{2} \mathrm{O}$-rich interstellar ice analogs produces amines, oxides of nitrogen, and nitriles. At least one of these nitriles produces an infrared feature near $2160 \mathrm{~cm}^{-1}$ that provides a good match to the so called "XCN" feature observed in the absorption spectra of dense molecular clouds surrounding protostars in the interstellar medium.

Insofar as the composition of interstellar ices are reflected in cometary ices, it is possible that HMT, XCN, and POM-like materials may comprise an important fraction of the complex organics in comets. Evaporation of these materials from $\mathrm{H}_{2} \mathrm{O}$ bearing grains in cometary comae could provide the extended source of the formaldehyde and cyanide seen in comets. Finally, HMT is known to hydrolyze under acidic conditions to yield ammonia and formaldehyde as well as amino acids. Since HMT incorporated into meteoritic parent bodies may be have experienced such conditions, it is possible that some of the amino acids in meteorites may have formed from HMT.

The presence of POM-like species in the photolysis residues lends support to the suggestion that such species are present in cometary organics. Such materials are made during both photolysis-warm up experiments and purely thermal warm up experiments, although the exact nature of the POM varieties produced is strongly dependent on the composition of the starting ice and radiation history. It should be stressed that, while POM-related species are commonly made, the pure "classical" linear form of POM, $\left(-\mathrm{CH}_{2} \mathrm{O}-\right)_{n}$, is not produced. Instead, POM-like species in which some of the $\mathrm{H}$ atoms and terminal groups are replaced by $-\mathrm{OH},-\mathrm{NH}_{2}$, etc., seem to be formed.

Preliminary studies carried out at other laboratories indicate that some of the species produced by ion irradiation differ from those produced by UV irradiation and that both are different from the products of purely thermal chemistry. Thus the organic compounds observed in cometary and interstellar ices could be diagnostic of their radiation history. Since it is possible that all three of these processes are important at one time or another in a comet's history, analyses of the species characteristic of each process in cometary nuclei would afford an opportunity to deduce the details of cometary chemical history. Thus, it is particularly important that these processspecific species be searched for during any cometary rendezvous mission that might be made.

This work was supported by NASA grants 452-33-93-03 (Origins of Solar Systems Program), 185-52-12-04 (Exobiology Program), and the NASA-ASEE Stanford Summer Faculty Fellowship Program. The authors are grateful to B. Khare (Cornell University) for the standard sample of HMT, R. B. Bohn, G. Cooper, M. Hanner, and D. Hudgins for fruitful discussions, $G$. Cooper and $C$. Lerner for assistance with the GC-MS, and R. Walker for excellent technical support. This paper also benefited from the comments of an anonymous reviewer.

\section{REFERENCES}

Agarwal, V. K., Schutte, W., Greenberg, J. M., Ferris, J. P., Briggs, R., Connor, S., van de Bult, C. P. E. M., \& Baas, F. 1985, Origins of life and Evolution of the Biosphere, 16, 21

Allamandola L. J \& Sandford S. A. 1988, in Dust in the Universe, ed. M. E. Bailey \& D. A. Williams (Cambridge: Cambridge Univ. Press), 229

Allamandola, L. J., Sandford, S. A., Tielens, A. G. G. M., \& Herbst, T. M. 1992, ApJ, 399, 134

Allamandola L. J, Sandford, S. A., \& Valero, G. J. 1988, Icarus, 76, 225

Arpigny, C. 1965, ARA\&A, 3, 351

Bellamy, L. J. 1960, The Infrared Spectra of Complex Molecules (New York: Wiley)

Bernstein, M. P., Sandford, S. A., Allamandola, L. J., \& Chang, S. 1994, J. Phys. Chem., 98, 12206

Bregman, J. D., Tielens, A. G. G. M., Witteborn, F. C., Rank, D. M., \& Wooden, D. 1988, ApJ, 334, 1044

Briggs, R., Ertem, G., Ferris, J. P., Greenberg, J. M., McCain, J. P., MendozaGomez, C. X., \& Schutte, W. 1992, Origins of Life and Evolution of the Biosphere, 22, 287

Buch, V. \& Devlin, J. P. 1994, ApJ, 431, L135

Bulterov, A. 1859, Ann. Chem., 11,250

Chang, S. 1979, in Space Missions to Comets, ed. M. Neugebauer, D. K. Yeomans, J C Brandt, \& R. W. Hobbs (NASA CP 2089), 59

Charnley, S. B., Kress, M. E., Tielens, A. G. G. M., \& Millar, T. J. 1995, ApJ, 448, 232

Charnley, S. B., Tielens, A. G. G. M., \& Millar, T. J. 1992, ApJ, 399, L71

Chyba, C. F., Thomas, P. J., Brookshaw, L., \& Sagan, C. 1990, Science, 249, 366

Combes, $M$, et al. 1988 , Icarus, 76,404

d'Hendecourt, L \& Allamandola, L J 1986, A\&AS, 64, 453 1986, A\&A, 158,119

d'Hendecourt, L. B., \& Jordain de Muizon, M. J. 1989, A\&A, 223, L5

DiSanti, M. A., Mumma, M. J., Geballe, T. R., \& Davies, J. K. 1995, Icarus, submitted

Dissly, R. W., Allen, M., \& Anicich, V. G. 1994, ApJ, 435, 685

Greenberg, J. M. 1982, in Submillimeter Wave Astronomy, ed. J. E. Beckman \& J. P. Phillips (Cambridge : Cambridge Univ. Press), 261
Greenberg J M \& Shalabiea O M 1994, in Asteroids, Comets, and Meteors 1993, ed. A. Milani et al. (Netherlands: IAU Press), 327

Gribov, L. A., \& Smirnov, V. N. 1962, Soviet Phys.-Uspekhi, 4, 919

Grim, R., \& Greenberg, J. M. 1987, ApJ, 321, L91

Hagen W Allamandola, L. J \& Greenberg, J. M. 1979, Ap\&SS, 65, 215

Hanner, M. S., Lynch, D. K., \& Russell, R. W. 1994, ApJ, 425, 274

Hoban, S., Reuter, D. C., DiSanti, M. A., \& Mumma, M. J. 1993, Icarus, 105 548

Hudgins, D. M., Sandford, S. A., Allamandola, L. J., \& Tielens, A. G. G. M. 1993, ApJS, 86, 713

Huebner, W. F. 1987, Science, 237,628

Huebner, W. F., Boice, D. C., \& Sharp, C. M. 1987, ApJ, 320, L149

Irvine, W. M., Goldsmith, P. F., \& Hjalmarson, A. 1987, in Interstellar Processes, ed. D. J. Hollenbach \& H. A. Thronson, Jr. (Dordrecht: Reidel) 561

Iwakami, Y., Takazono, M., \& Tsuchiya, T. 1968, Bull. Chem. Soc. Japan, 41, 813

Johnson, R. E., Cooper, J. F., \& Lanzerotti, L. J. 1986, in Proc. 20th ESLAB Symp. on Exploration of Halley's Comet, Heidelberg (ESA SP-250), 269

Kargel, J. S. 1992, Icarus, 100, 556

Khare, B. N., \& Sagan, C. 1973, in Molecules in the Galactic Environment, ed M. A. Gordon, \& L. E. Snyder (New York: Wiley), 400

Klavetter, J. J., \& A'Hearn, M. F. 1994, Icarus, 107, 322

Knacke, R. F. McCorkle, S., Puetter, R. C., Erickson, E. F., \& Kratschmer, W $1982, \mathrm{ApJ}, 260,141$

Lacy, J. H., Baas, F., Allamandola, L. J., Persson, S. E., McGregor, P. J. Lonsdale, C. J., Geballe, T. R., \& van de Bult, C. E. P. 1984, ApJ, 276, 533

Lacy, J. H., Carr, J. S., Evans II, N. J., Baas, F., Achtermann, J. M., \& Arens, J. F. 1991, ApJ, 376, 556

Larson, H. P., Weaver, H. A., Mumma, M. J., \& Drapatz, S. 1989, ApJ, 338, 1106

Mauersberger, R., Wilson, T. L., Mezger, P. G., Gaume, R., \& Johnston, K. J. 1992, A\&A, 256, 640

Millar, T. J., Olofsson, H., Hjalmarson, A., \& Brown, P. D. 1988, A\&A, 205, L5 Mitchell, D. L., Lin, R. P., Carlson, C. W., Korth, A., Reme, H., \& Mendis, D. A. 1992, Icarus, 98,125 
Moore, M. H., Donn, B., Khanna, R., \& A'Hearn, M. F. 1983, Icarus, 54, 388

Moore, M. H., \& Tanabé, T. 1990, ApJ, 365, L39

Moore, M. H., Tanabé, T., \& Nuth, J. A. 1991, ApJ, 373, L31

Norman, C., \& Silk, J. 1980, ApJ, 238, 158

Nuth, J. A., \& Moore, M. H. 1988, ApJ, 329, L113

Oro, J. 1961, Nature, 190,389

Prasad, S. S., \& Tarafdar, S. P. 1983, ApJ, 267,603

Reuter, D. C. 1992, ApJ, 386, 330

Sagan, C., \& Khare, B. N. 1970, BAAS, 2, 340

Sandford, S. A. 1984, Icarus, 60, 115

Sandford, S. A., \& Allamandola, L. J. 1993a, ApJ, 417,815

. 1993b, ApJ, 409, L65

Sandford, S. A., Allamandola, L. J., \& Geballe, T. R. 1993, Science, 262, 400 Sandford, S. A., Allamandola, L. J., Tielens, A. G. G. M., \& Valero, G. J. 1988, ApJ, 329, 498

Schutte, W. A. 1988, Ph.D. thesis, Univ. Leiden

Schutte, W. A., Allamandola, L. J., \& Sandford, S. A. 1993a, Icarus, 104, 118 1993b, Science, 259, 1143

Schutte, W. A., Gerakines, P. A., van Dishoeck, E. F., Greenberg, J. M., \&

Geballe, T. R. 1994, in AIP Conf. Proc. 312, Physical Chemistry of Molecules and Grains in Space, ed. I. Nenner (New York: AIP), 73
Silverstein, R. M., \& Bassler, G. C. 1963, Spectrometric Identification of Organic Compounds (New York: Wiley)

Smolin, E. M., \& Rapoport, L. 1959, S-Triazines \& Derivatives (New York: Interscience), 545

Soifer, B. T., Puetter, R. C., Russell, R. W., Willner, S. P., Harvey, P. M., \& Gillett, F. C. 1979, ApJ, 232 L.53

Tegler, S. C., Weintraub, D. A. Allamandola, L. J., Sandford, S. A., Rettig, T. W., \& Campins, H. 1993, ApJ, 411, 260

Tielens, A. G. G. M., Tokunaga, A. T., Geballe, T. R., \& Baas, F. 1991, ApJ, 381,181

Turner, B. E. 1991, ApJS, 76, 617

Warnek, P. 1962, Appl. Opt., 1, 721

Wexler, A.S. 1967, Appl. Spectrosc. Rev., 1, 29

Wolman, Y., Miller, S. L., Ibanez, J., \& Oro, J. 1971, Science, 174, 1039

Walker, J. F. 1964, Formaldehyde (New York : Reinhold), 511

Zuckerman, B., et al. 1975, ApJ, 196, L99 